\title{
Development of a Dopamine- and Cyclic Adenosine 3':5'-Monophosphate-Regulated Phosphoprotein (DARPP-32) in the Prenatal Rat Central Nervous System, and Its Relationship to the Arrival of Presumptive Dopaminergic Innervation
}

\author{
George A. Foster, ${ }^{1}$ Marianne Schultzberg, Tomas Hökfelt, Menek Goldstein, ${ }^{2}$ Hugh C. Hemmings, Jr., ${ }^{3}$ \\ Charles C. Ouimet, ${ }^{3}$ S. Ivar Walaas, ${ }^{3}$ and Paul Greengard ${ }^{3}$ \\ Department of Histology, Karolinska Institute, S-104 01 Stockholm, Sweden, 'Department of Physiology, University \\ College, Cardiff CF1 1XL, United Kingdom, '2Department of Psychiatry, New York University Medical Center, New York, \\ New York 10016, and 'Laboratory of Molecular and Cellular Neuroscience, The Rockefeller University, New York, New \\ York 10021
}

The development of a dopamine- and adenosine $3^{\prime}: 5^{\prime}$-monophosphate-regulated phosphoprotein with an apparent $M_{\mathrm{r}}$ of 32,000 (DARPP-32) has been investigated in the central nervous system of the prenatal and newborn rat by immunocytochemical methods. DARPP-32 first appears in the rat brain at day 14 of gestation, in the anlage of the primary olfactory cortex and the caudate nucleus. Over the next few days, the number of immunoreactive cell bodies in these 2 areas, and in the olfactory tubercle and frontal cortex, increases rapidly. By the day of birth, most of the brain regions that will ultimately contain DARPP-32-positive somata already display a disposition toward DARPP-32-like immunoreactivity similar to that observed in the adult animal. In addition to the nuclei mentioned above, DARPP-32-containing cell bodies also appear over the intervening period in the olfactory nucleus, nucleus accumbens, central amygdaloid nucleus, lateral funiculus, and the choroid plexus and ependymal layers of the third, fourth, and lateral ventricles and the Sylvian aqueduct. Many of these immunoreactive cells disappear during subsequent postnatal maturation.

DARPP-32-immunoreactive fibers were also observed in the prenatal and newborn rat CNS. As in the adult, the processes were observed in known target areas of the DARPP. 32-containing neurons, namely, the globus pallidus, ventral pallidum, internal capsule, and substantia nigra.

The ontogeny of tyrosine hydroxylase (TH)-like immunoreactivity was analyzed simultaneously. Of particular interest was the observation that the arrival within a given brain region of the presumed dopaminerglc, TH-containing innervation, part of whose postsynaptic function is putatively mediated by DARPP-32, was preceded by at least $2 \mathrm{~d}$ by the appearance of the DARPP-32-containing cells. Moreover, the subsequent reorganization of the DARPP-32-positive so-

\footnotetext{
Received Jan. 24, 1986; revised Apr. 22, 1986; accepted May 28, 1986.

These studies were supported by grants from the Swedish Medical Research Council (04X-2887), the Alice och Knut Wallenbergs Stiftelse, the Magnus Bergvalls Stiftelse, and the Karolinska Institute, and by Grant NS06801 from the National Institute of Neurological and Communicable Diseases and Stroke, MHO2714 and MH40899 from the National Institute of Mental Health. G.A.F. is a Royal Society Research Fellow. We thank Ms. W. Hiort for photographic assistance.

Correspondence should be addressed to Tomas Hökfelt, Department of Histology, Karolinska Institute, P.O. Box 60400, S-104 01 Stockholm, Sweden.

Copyright (C) 1987 Society for Neuroscience 0270-6474/87/071994-25\$02.00/0
}

mata within the caudate nucleus into distinct clumps also predated by 1 or $2 \mathrm{~d}$ the aggregation of the TH fibers into the same microzones.

The development of DARPP-32-like immunoreactivity is mostly complete by the day of birth, and is consistent with its playing a role in mediating some of the postsynaptic actions of dopamine pathways. The appearance of this protein does not seem to be dependent on the presence of a dopaminergic innervation.

Ouimet et al. (1984) have recently reported an immunocytochemical analysis of the localization of dopamine (DA) and adenosine $3^{\prime}: 5^{\prime}$-monophosphate-regulated phosphoprotein (DARPP-32), a cytosolic protein with an apparent $M_{\mathrm{r}}$ of 32,000 , whose phosphorylation state is controlled in intact cells by both DA and cyclic AMP (Walaas et al., 1983; Hemmings et al., 1984b; S. I. Walaas and P. Greengard, unpublished observations). The greatest DARPP-32-like immunoreactivity (DARPP$32-\mathrm{LI})$ resided in neurons thought to receive dopaminergic afferents. These included cell somata and dendrites in the caudatoputamen, nucleus accumbens, olfactory tubercle, bed nucleus of the stria terminalis, and parts of the amygdaloid complex. In addition, the axonal processes considered to arise from these cells and terminating in areas including the globus pallidus, ventral pallidum, entopeduncular nucleus, and the substantia nigra (Nauta and Domesick, 1979) also displayed intense DARPP-32-LI. The immunohistochemical data, showing a striking overlap between DARPP-32-immunoreactive neurons and DA-containing nerve terminals, and the regulation of DARPP-32 phosphorylation by DA (Walaas et al., 1983; Walaas and Greengard, 1984) supported the notion that the protein was involved in mediating some of the postsynaptic effects of dopamine. Biochemical studies suggest that DARPP-32 may achieve some of these effects by acting as a potent and specific inhibitor, in its phosphorylated form, of the enzyme protein phosphatase-1 (Hemmings et al., 1984a).

In order to determine at what age the functional properties effectcd by DARPP-32 in the dopaminoceptive cells might become apparent, the ontogeny of this protein in the developing rat CNS was analyzed immunohistochemically. In addition, in view of the specific relationship hypothesized between DARPP32 and DA, the development of tyrosine hydroxylase (TH), the 
A

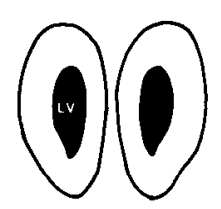

B
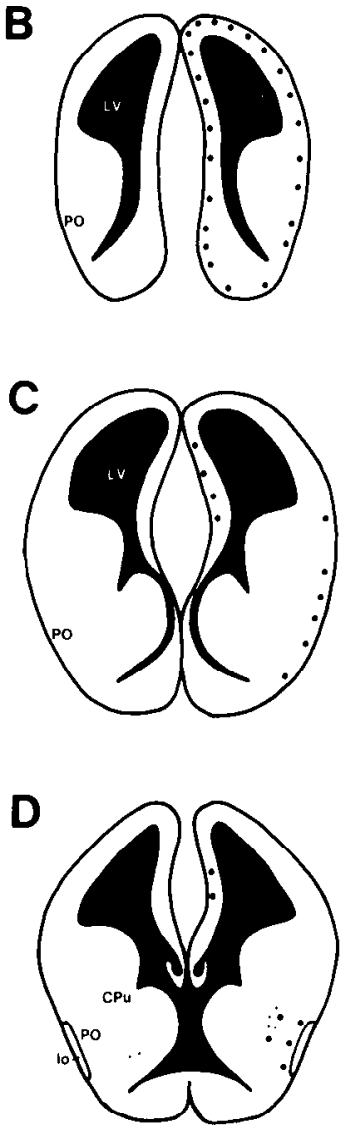

E
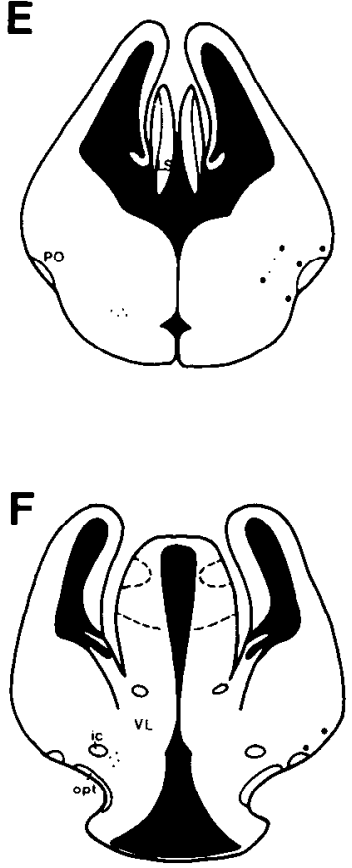

G

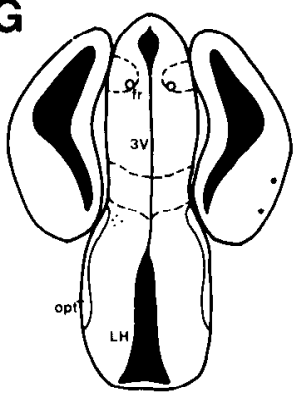

H

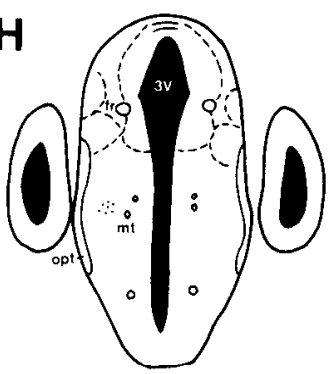

$\mid$

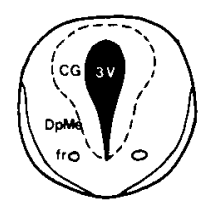

$J$

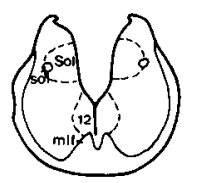

K

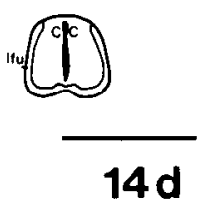

Figure 1. Diagrams of frontal sections at various levels through the rat brain on day 14 of gestation. Large dots indicate 3-5 DARPP-32-immunoreactive cell bodies in a $14 \mu \mathrm{m}$ section. Small dots on the right-hand side are related to the density of DARPP-32-positive fibers, while the small dots on the lefthand side indicate the density of $\mathrm{TH}$ immunoreactive innervation. The latter symbols have only been used where relevant, but refer to the same side of the brain section as the DARPP-32 dots. Abbreviations are listed in the text. rate-limiting enzyme in DA synthesis, was simultaneously analyzed.

\section{Materials and Methods}

Antibodies. Antibodies against DARPP-32 were produced essentially by the techniques of Köhler and Milstein (1975). In brief, hybridomas of spleen cells from BALB/c mice that had previously been immunized with purified bovine DARPP-32 (Hemmings et al., 1984a) and Sp2/0 $\mathrm{Ag} 14$ myeloma cells, were analyzed using a coprecipitation antigenbinding assay, with protein A-bearing Staphylococcus aureus cells as an immunoadsorbent. BALB/c mice were injected intraperitoneally with positive cultures, and the ascites fluid collected. A mixture of 3 of the resultant monoclonal antibodies (C24a-5a, C24a-6a, and C24a-4D7) was used in the present experiments. The specificity of the antibodies was validated by immunoprecipitation and immunoblotting as described previously (Ouimet et al., 1984; Hemmings and Greengard, 1986).

TH was isolated from a rat clonal pheochromocytoma cell line (Markey et al., 1980), and antibodies raised in rabbits. The specificity of the antisera was analyzed as previously described (Markey et al., 1980).

In some embryos, immunocytochemical controls were also used. Sections adjacent to those stained for DARPP-32-LI were treated with antiserum previously incubated for $6 \mathrm{hr}$ with purified DARPP-32 or with normal mouse serum (1:200 dilution). Positive staining was defined by its presence in the former section, but its absence in the latter.

Immunocytochemistry. Sprague-Dawley rats (ALAB, Stockholm) were used. Seven female rats and 1 male were placed together overnight. The following morning, the females were inspected for vaginal plugs. The day after successful impregnation was designated gestational day 1 .

Pregnant rats at various gestational stages were anesthetized with $7 \%$ chloral hydrate; the embryos were removed, and the length between the rats' crowns and rumps (CRL) measured. Thereafter, the brain and spinal cord were dissected under the surface of an ice-cold fixative solution. This was either $4 \%$ freshly prepared paraformaldehyde (PF) (Pease, 1962 ) or $4 \% \mathrm{PF}$ and $0.2 \%$ picric acid (Zamboni and de Martino, 1967), both in $0.1 \mathrm{M}$ phosphate buffer, $\mathrm{pH} 7.4$. The dissected tissue was left in the same fixative for $2 \mathrm{hr}$ at $4^{\circ} \mathrm{C}$, and then placed in $0.1 \mathrm{M}$ phosphate buffer, $\mathrm{pH} 7.4$, containing $10 \%$ sucrose at $4^{\circ} \mathrm{C}$ for at least 24 hir.

Embryonic brains and spinal cords were then frozen and cut on a cryostat (Dittes, Heidelberg) in either the sagittal or transverse planes at a thickness of $14 \mu \mathrm{m}$. The sections were placed on glass slides previously coated with a mixture of chrom-alum and gelatin, and were then thawed. Serial sections were stained with cresyl violet or for DARPP32- or TH-LI. Immunostaining was performed by the standard indirect fluorescence method of Coons and his collaborators (see Coons, 1958). Briefly, sections were rinsed for $10 \mathrm{~min}$ with $0.1 \mathrm{~m}$ phosphate buffer, pH 7.4, containing $0.9 \% \mathrm{NaCl}$ (PBS), and antibodies against either DARPP-32 (diluted 1:200) or TH (diluted 1:400) were applied for 18 $\mathrm{hr}$ at $4^{\circ} \mathrm{C}$ in a moist environment. The sections were then rinsed twice in PBS for $10 \mathrm{~min}$. FITC-conjugated antibodies were used. For sections previously incubated with DARPP-32 antibodies, rat anti-mouse IgA + 
1996 Foster et al. - Adenosine 3':5'-Monophosphate-Regulated Phosphoprotein in Prenatal Rat CNS

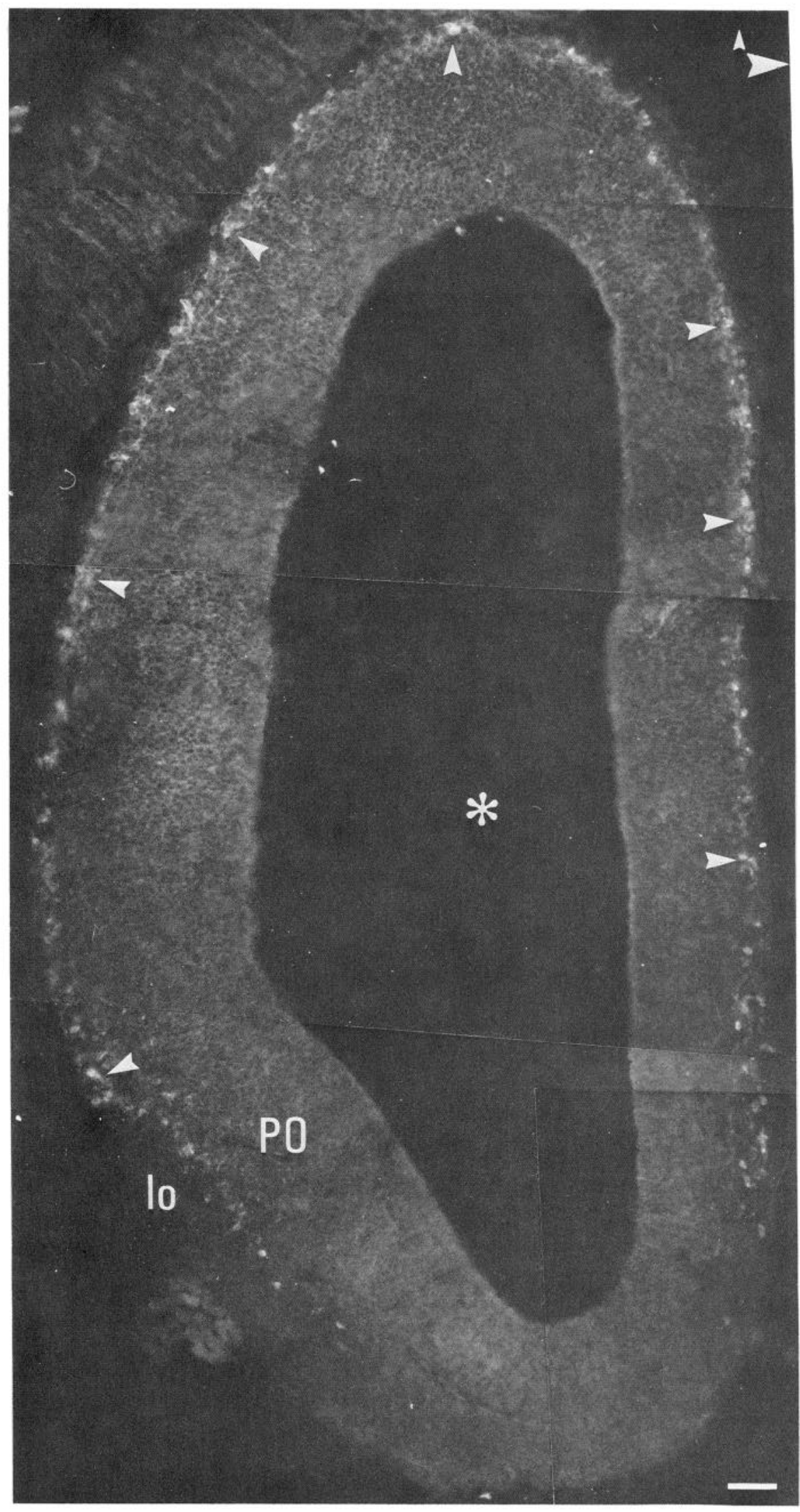

Figure 2. Immunofluorescence photomicrograph of DARPP-32-LI in the forebrain of the embryonic $14 \mathrm{~d}$ rat. Immunoreactive cells are found initially around most of the perimeter of the forebrain (arrowheads) and seem not to be restricted by any known anatomical boundaries. $l o$, Lateral olfactory tract; $P O$, primary olfactory cortex. Asterisk indicates lateral ventricle. Small arrowhead in top right corner points dorsally and big arrowhead medially. Scale bar, $50 \mu \mathrm{m}$. 
- A

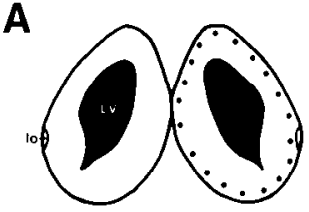

B

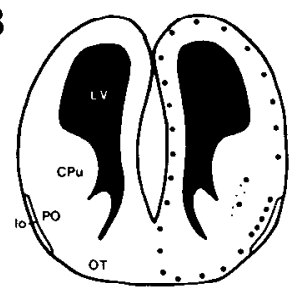

C
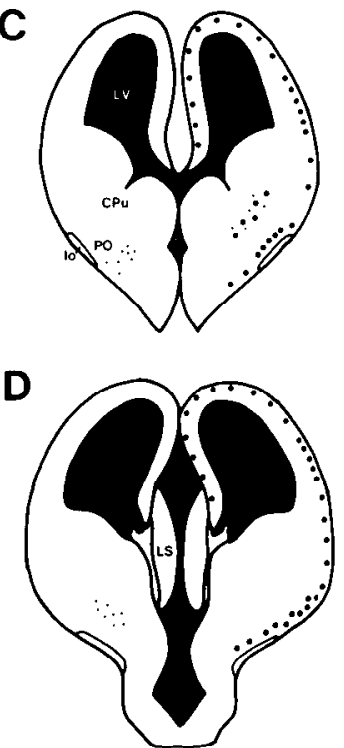

E

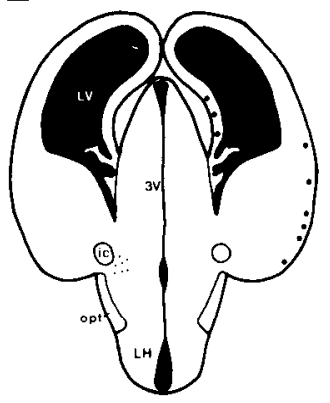

$\mathbf{F}$

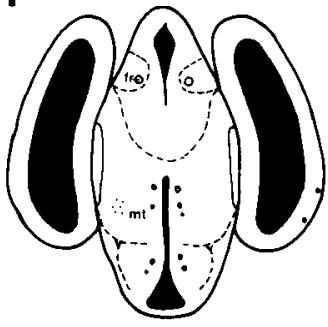

G

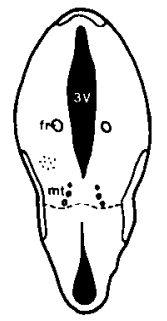

H
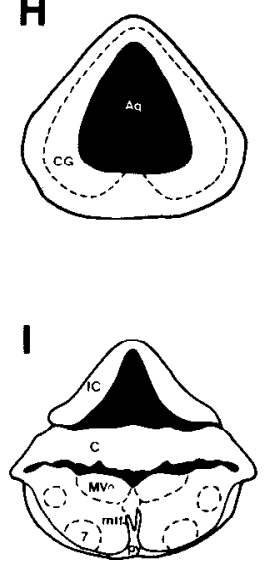

J

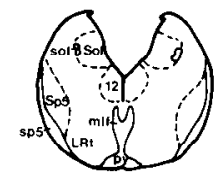

K

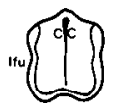

Figure 3. Diagrams of frontal sections at various levels through the rat brain on day 15 of gestation. Large dots indicate 3-5 DARPP-32-immunoreactive cell bodies in a $14 \mu \mathrm{m}$ section. Small dots on the right-hand side are related to the density of DARPP-32-positive fibers, while the small dots on the lefthand side indicate the density of THimmunoreactive innervation. The lattcr symbols have only been used where relevant, but refer to the same side of the brain section as the DARPP-32 dots. Abbreviations are listed in the text.
IgG + IgM antisera $\left(1: 10\right.$; Cappel, PA) were applied for $30 \mathrm{~min}$ at $37^{\circ} \mathrm{C}$. Similarly, sections previously treated with $\mathrm{TH}$ antibodies were incubated with swine anti-rabbit antibodies linked to FITC (1:10; Dakopatts, Copenhagen) at $37^{\circ} \mathrm{C}$. The sections were washed twice with PBS, then mounted in a mixture of glycerol and PBS (3:1) containing $0.2 \% p$-phenylenediamine to prevent fading of the fluorochrome (Johnson and De C Nogueira Araujo, 1981).

Sections were examined in a Zeiss fluorescence microscope fitted with an oil dark-field condenser. A KP500 excitation filter and an LP520 stop filter, with Scopix RP1 black-and-white film (Gevaert, Belgium) were used for photography. All micrographs in this paper were taken from transverse sections.

Drawings were made of the embryonic brain at various levels in the frontal plane, and details of the number of DARPP-32-positive cell somata recorded, with the approximate density of immunoreactive fibers. These are indicated on the right-hand sides of Figures 1, 3, 4, 7, $8,10,13$, and 17 by large dots (equivalent to $3-5$ cell bodies) and small dots (approximately related to fiber density). TH-immunoreactive fibers are also indicated, where relevant, by small dots on the left side of each diagram, but correspond to the same side of the original section as the symbols for the DARPP-32-LI.

The abbreviations used were based on the atlas of Paxinos and Watson (1982): nucleus accumbens ( $=$ NA)
$\mathrm{Amb}$

$\mathrm{Aq}$

Arc

BST

BSTM

$\mathrm{C}$

$\mathrm{CC}$

$\mathrm{cc}$

$\mathrm{CG}$

cp

$\mathrm{CPu}$

$\mathrm{Cu}$

DpMe

DR

ec

f

fi

fmi

Fr

fr

FrPaM

FrPaSS

FStr

GP

IC

ic

icp

IG

IO

IP nucleus ambiguus

cerebral aqueduct

arcuate hypothalamic nucleus

bed nucleus of the stria terminalis

bed nucleus of the stria terminalis, medial part cerebellum

central canal

corpus callosum

central (periaqueductal) gray

cerebral peduncle, basal

caudate putamen (striatum)

cuneate nucleus

deep mesencephalic nucleus

dorsal raphe

external capsule

fornix

fimbria of the hippocampus

corpus callosum, forceps minor

frontal cortex

fasciculus retroflexus

frontoparietal cortex, presumptive motor area

frontoparietal cortex, presumptive somatosensory area fundus striati

globus pallidus

inferior colliculus

internal capsule

inferior cerebellar peduncle

induseum griseum

inferior olive

interpeduncular nucleus 
Figure 4. Diagrams of frontal sections at various levels through the rat brain on day 16 of gestation. Large dots indicate 3-5 DARPP-32-immunoreactive cell bodies in a $14 \mu \mathrm{m}$ section. Small dots on the right-hand side are related to the density of DARPP-32-positive fibers, while the small dots on the lefthand side indicate the density of THimmunoreactive innervation. The latter symbols have only becn used wherc relevant, but refer to the same side of the brain section as the DARPP-32 dots. Abbreviations are listed in the text.
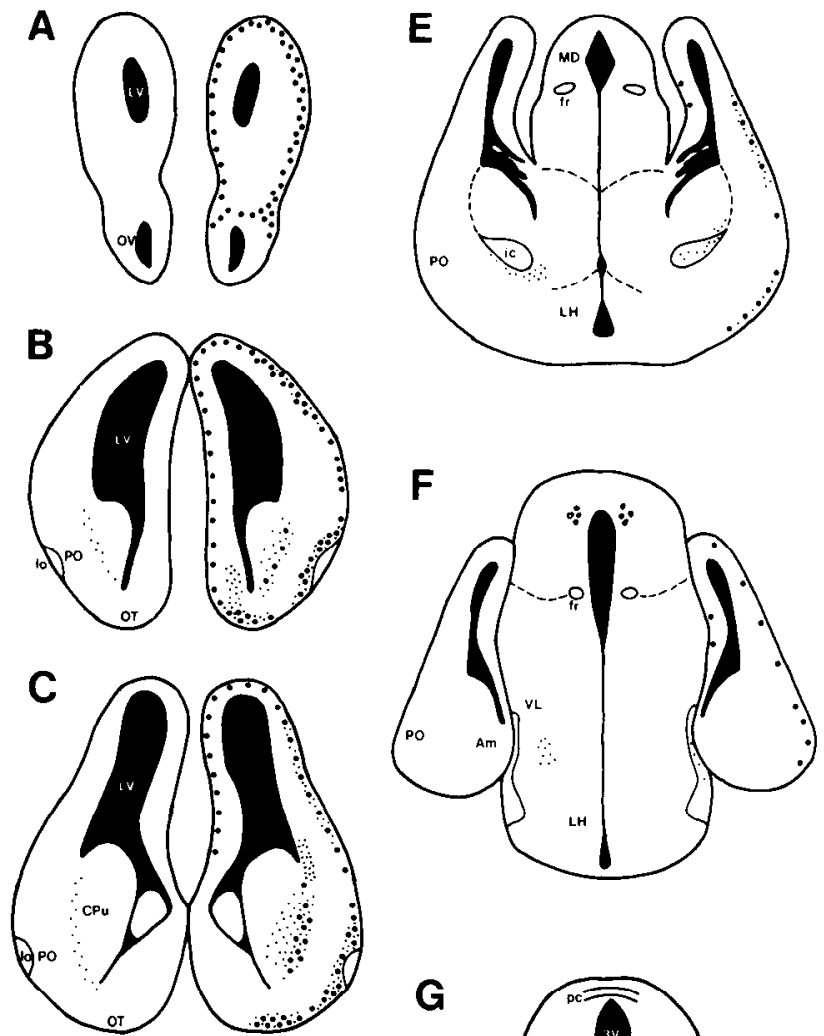

$\mathrm{H}$
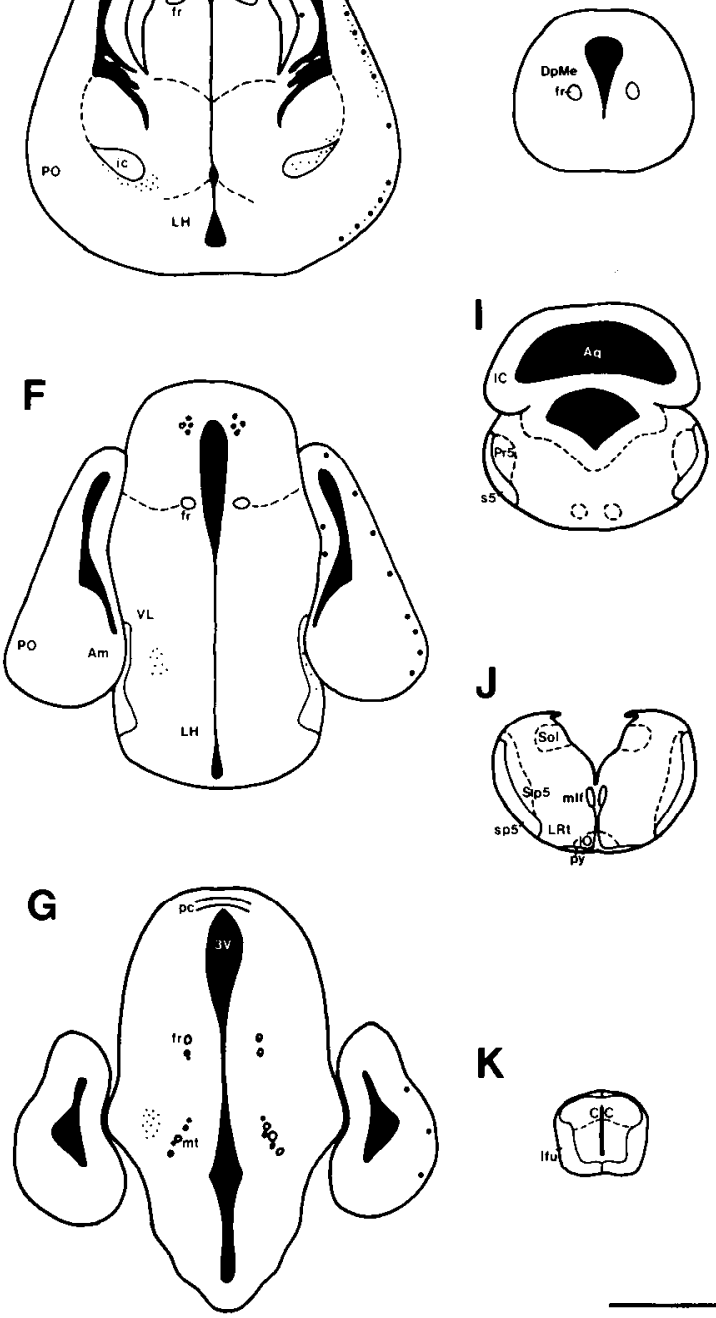

K
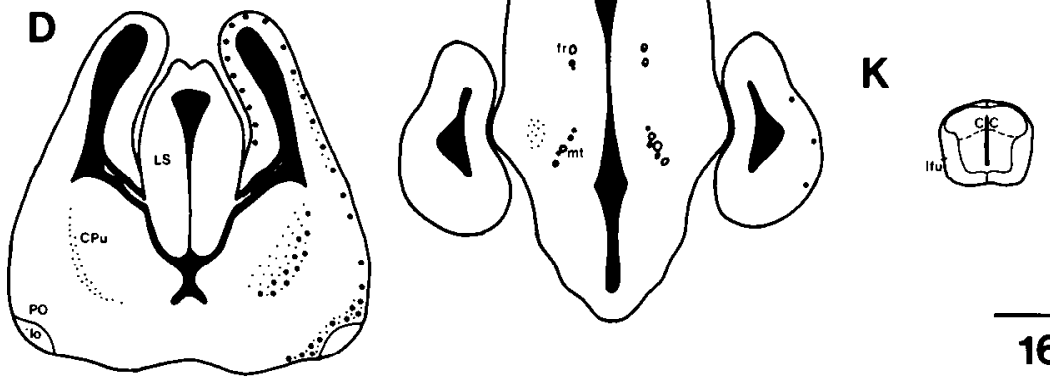

$16 d$

$\begin{array}{ll}\text { LC } & \text { locus coeruleus } \\ \text { Ifu } & \text { lateral funiculus } \\ \text { LH } & \text { lateral hypothalamus } \\ \text { ll } & \text { lateral lemniscus } \\ \text { lo } & \text { lateral olfactory tract } \\ \text { LRt } & \text { lateral reticular nucleus } \\ \text { LS } & \text { lateral septum } \\ \text { LV } & \text { lateral ventricle } \\ \text { MD } & \text { mediodorsal thalamus } \\ \text { Me } & \text { median eminence } \\ \text { MHab } & \text { medial habenula } \\ \text { mlf } & \text { medial longitudinal fasciculus } \\ \text { mt } & \text { mammillothalamic tract } \\ \text { MVe } & \text { medial vestibular nucleus } \\ \text { NA } & \text { nucleus accumbens (=Acb) }\end{array}$

$\begin{array}{ll}\text { ON } & \text { olfactory nerve layer } \\ \text { opt } & \text { optic tract } \\ \text { OV } & \text { olfactory ventricle } \\ \text { OT } & \text { olfactory tubercle }(=\mathrm{Tu}) \\ \text { ox } & \text { optic decussation } \\ \text { PA } & \text { gigantocellular reticular nucleus, pars alpha } \\ \text { Pa } & \text { paraventricular nucleus } \\ \text { pc } & \text { posterior commissure } \\ \text { PF } & \text { parafascicular thalamic nucleus } \\ \text { PGi } & \text { paragigantocellular reticular nucleus } \\ \text { PO } & \text { primary olfactory cortex } \\ \text { PrH } & \text { prepositus hypoglossal nucleus } \\ \text { Pr5 } & \text { principal sensory trigeminal nucleus } \\ \text { py } & \text { pyramidal tract } \\ \text { RCh } & \text { retrochiasmatic area }\end{array}$

Figure 5. Immunofluorescence photomicrographs of DARPP-32-LI $(A)$ and TH-LI $(B)$ in the forebrain of the embryonic $16 \mathrm{~d}$ rat. The peripheral zone of DARPP-32-immunoreactive cells has increased at $16 \mathrm{~d}$ and DARPP-32-containing neurons have become visible in the primordial caudate nucleus and olfactory tubercle $(\mathrm{Tu})$. Large numbers of cells with strong DARPP-32-LI are found in the medial cortex (arrowheads). Arrows delineate the approximate borderline between the caudate proper (laterally) and the proliferative and migratory layers (medially). Large arrow indicates the primordial nucleus accumbens. $B$, Distribution of TH-LI in an adjacent section, as indicated by rectangle in $A$. Note how few TH-positive fibers exist in this area compared to the numerous DARPP-32-positive cell bodies and fibers. Asterisk in $A$ indicates lateral ventricle. Small arrowhead in the top right corner of $A$ points dorsally and big arrowhead medially, Bar, $50 \mu \mathrm{m}$. $C P u$, Nucleus caudatus putamen: $l o$, lateral olfactory tract; $P O$, primary olfactory cortex. $T H$ in $B$ and in following figures indicates staining with tyrosine hydroxylase antiserum. Both photographs have the same magnification. 


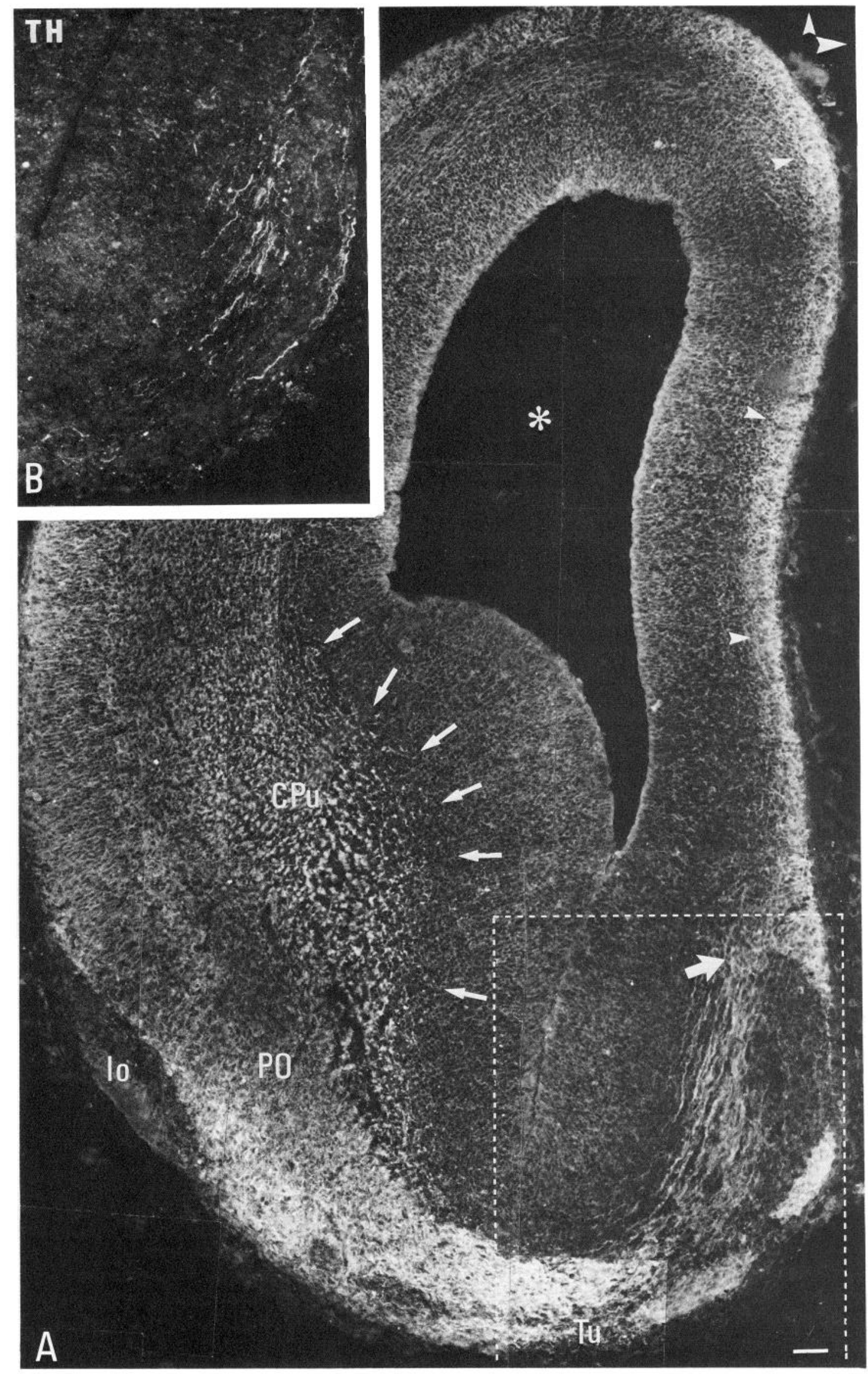



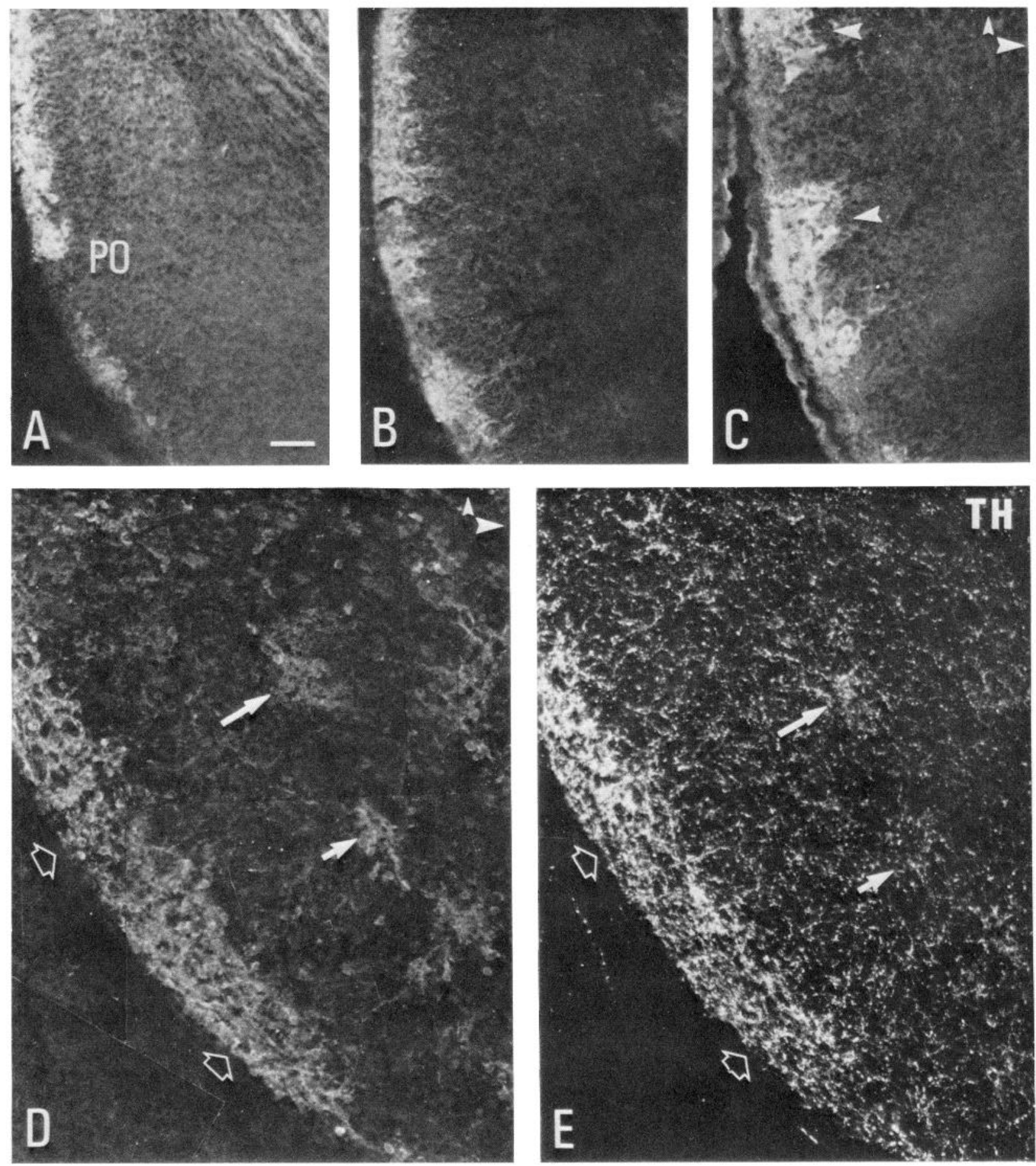

Figure 6. Immunofluorescence photomicrographs of DARPP-32-LI in the primary olfactory cortex $(P O)(A-C)$ of the $16 \mathrm{~d}(A), 17 \mathrm{~d}(B)$, and 19 $\mathrm{d}(C)$ embryonic rat and of the caudate nucleus of the $20 \mathrm{~d}$ embryonic rat stained for DARPP-32-LI $(D)$ and TH-LI $(E)$. $A-C$, Many DARPP-32positive cells are manifest on day 16, and on day 17 they appear to be organized into several small clumps, or subnuclei; these aggregates of DARPP-32-immunoreactive cells are even more obvious on day 19 (big arrowheads in $C$ ). $D, E$, Clusters of DARPP-32-immunoreactive cells (arrows in $D$ ) can be seen within the nucleus caudatus putamen and at its lateral border with the frontoparietal cortex (open arrows). A few cells are seen outside these clusters. Analysis of the adjacent sections stained for TH shows that, at this age, 1 or 2 of the cell aggregates also exhibit a slightly denser than normal collection of TH-positive fibers (arrows in E), but they are hard to distinguish from the relatively homogenous distribution of TH processes. The correlation between the lateral band of DARPP-32-positive cells and densely packed TH-immunoreactive fibers is, however, clear. Small arrowhead in upper right corner of $C$ and $D$ points dorsally, big arrowheads medially. Bar, $50 \mu \mathrm{m}$. All micrographs have the same magnification. 


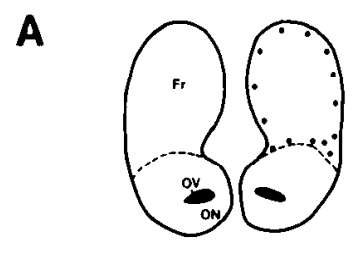

B
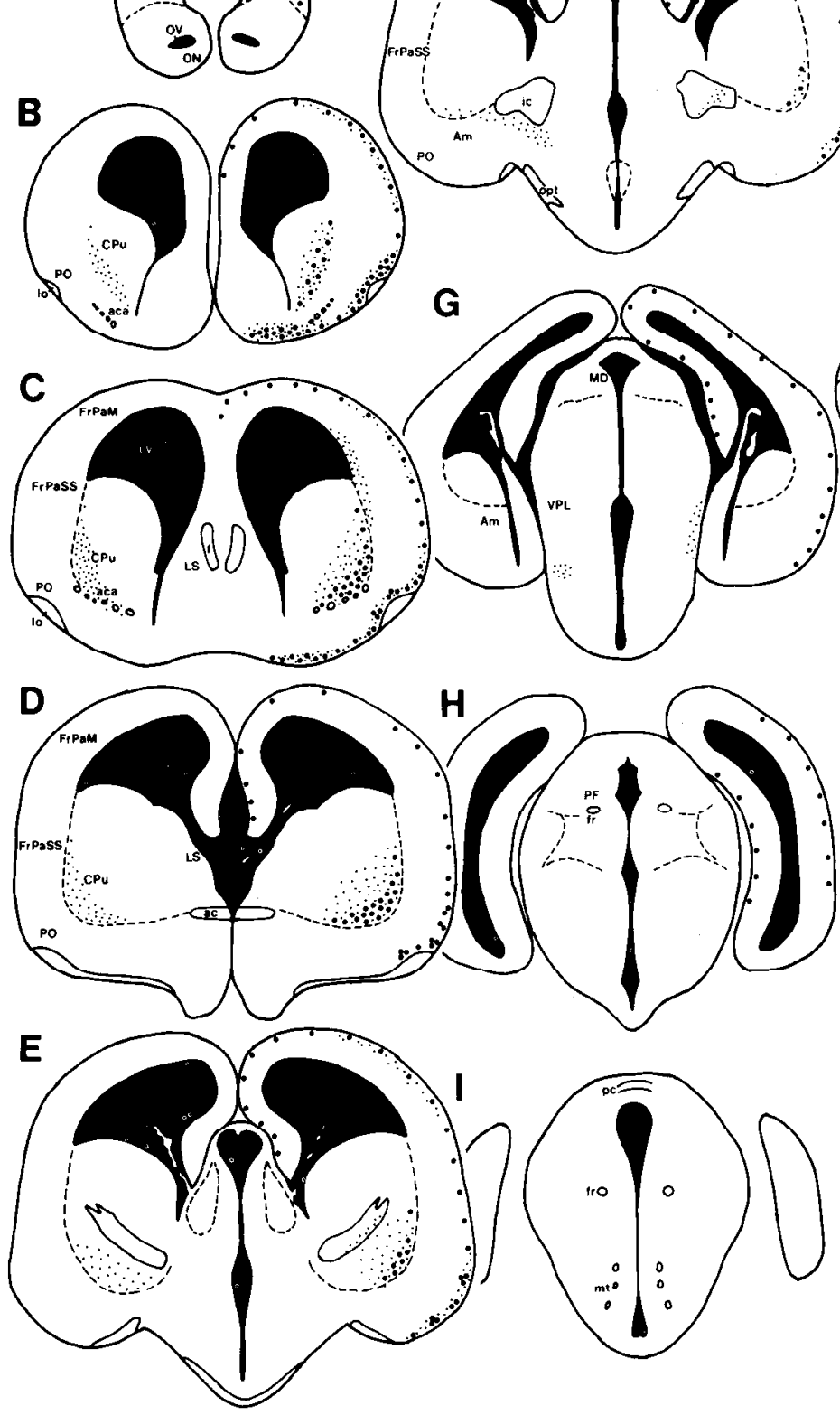

$\mathbf{N}$

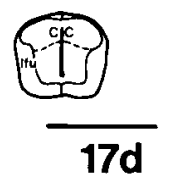

Figure 7. Diagrams of frontal sections at various levels through the rat brain on day 17 of gestation. Large dots indicate 3-5 DARPP-32-immunoreactive cell bodies in a $14 \mu \mathrm{m}$ section. Small dots on the right-hand side are related to the density of DARPP-32-positive fibers, while the small dots on the lefthand side indicate the density of $\mathrm{TH}$ immunoreactive innervation. The latter symbols have only been used where relevant, but refer to the same side of the brain section as the DARPP-32 dots. Abbreviations are listed in the text. raphe obscurus

reticular thalamic nucleus

superior colliculus

substantia nigra

nucleus of solitary tract

solitary tract

nucleus of spinal tract trigeminal nerve

spinal tract trigeminal nerve

stria terminalis

sensory root of the trigeminal nerve

thalamus

tectospinal tract

tubcrculum olfactorium $(=\mathrm{OT})$

ventrolateral thalamic nucleus

ventral nucleus of the lateral lemniscus

ventroposterior thalamic nucleus, lateral part

ventral tegmental area (Tsai)

zona incerta

$\begin{array}{ll}2 \mathrm{n} & \text { optic nerve } \\ 3 \mathrm{~V} & \text { third ventricle } \\ 4 \mathrm{~V} & \text { fourth ventricle } \\ 7 & \text { facial nucleus } \\ 12 & \text { hypoglossal nucleus }\end{array}$

\section{Results}

Day 13 of gestation $(C R L=9.5 \mathrm{~mm})$

Six embryos were examined in either the transverse or the longitudinal plane. No structures containing DARPP-32-LI could be detected in embryos fixed at this stage of gestation. By contrast, many TH-positive cell bodies and processes were found in the substantia nigra, the medulla oblongata, and parts of the ventrolateral spinal cord, as has previously been described (Specht et al., 1981a, b; Foster et al., 1985a, b). 


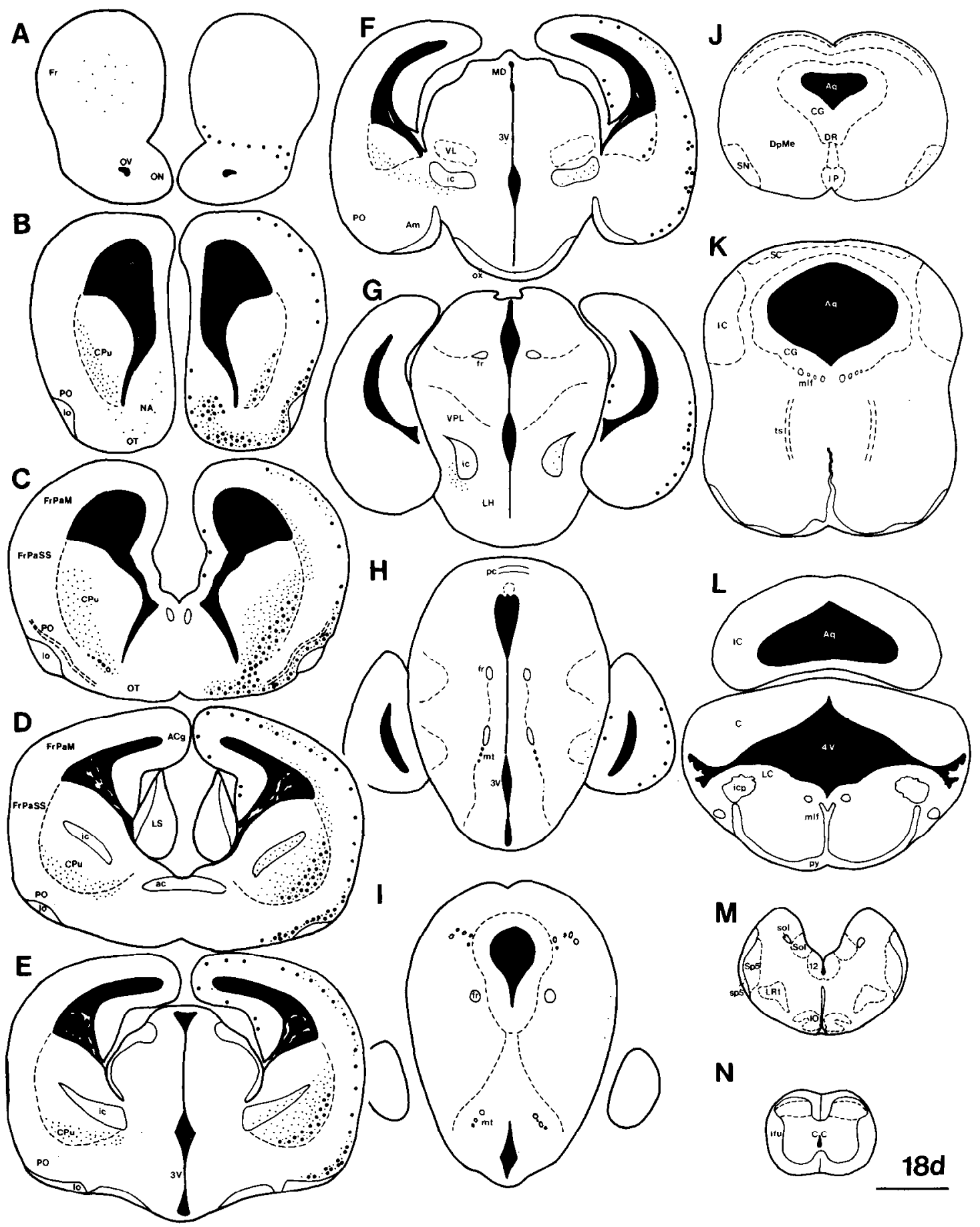

Figure 8. Diagrams of frontal sections at various levels through the rat brain on day 18 of gestation. Large dots indicate 3-5 DARPP-32immunoreactive cell bodies in a $14 \mu \mathrm{m}$ section. Small dots on the right-hand side are related to the density of DARPP-32-positive fibers, while the small dots on the left-hand side indicate the density of TH-immunoreactive innervation. The latter symbols have only been used where relevant, but refer to the same side of the brain section as the DARPP-32 dots. Abbreviations are listed in the text.

Day 14 of gestation (CRL $=13 \mathrm{~mm}$ ) (Fig. 1)

Six embryos were used. The first cells containing DARPP-32 were found in embryos of this gestational age. Cells immunoreactive to DARPP-32 antibodies were apparent in the rostral part of the primordial olfactory tubercle at day 14 of gestation. Indeed, at the most rostral extent of the forebrain, many cells at its circumference appeared DARPP-32-positive (Fig. 2). No processes were apparent, though. No TH-immunoreactive structures could be detected in this brain area.

Many weakly DARPP-32-immunoreactive somata were also visible in the primary olfactory cortex (Figs. $1, B-E ; 2$ ) and a few in the frontoparietal cortex (Fig. 2), but no processes could be found in these areas. The exact boundaries between the anlage of these brain regions were indistinct. In the caudate nucleus, 1 or 2 very weakly DARPP-32-positive neurons were apparent, 

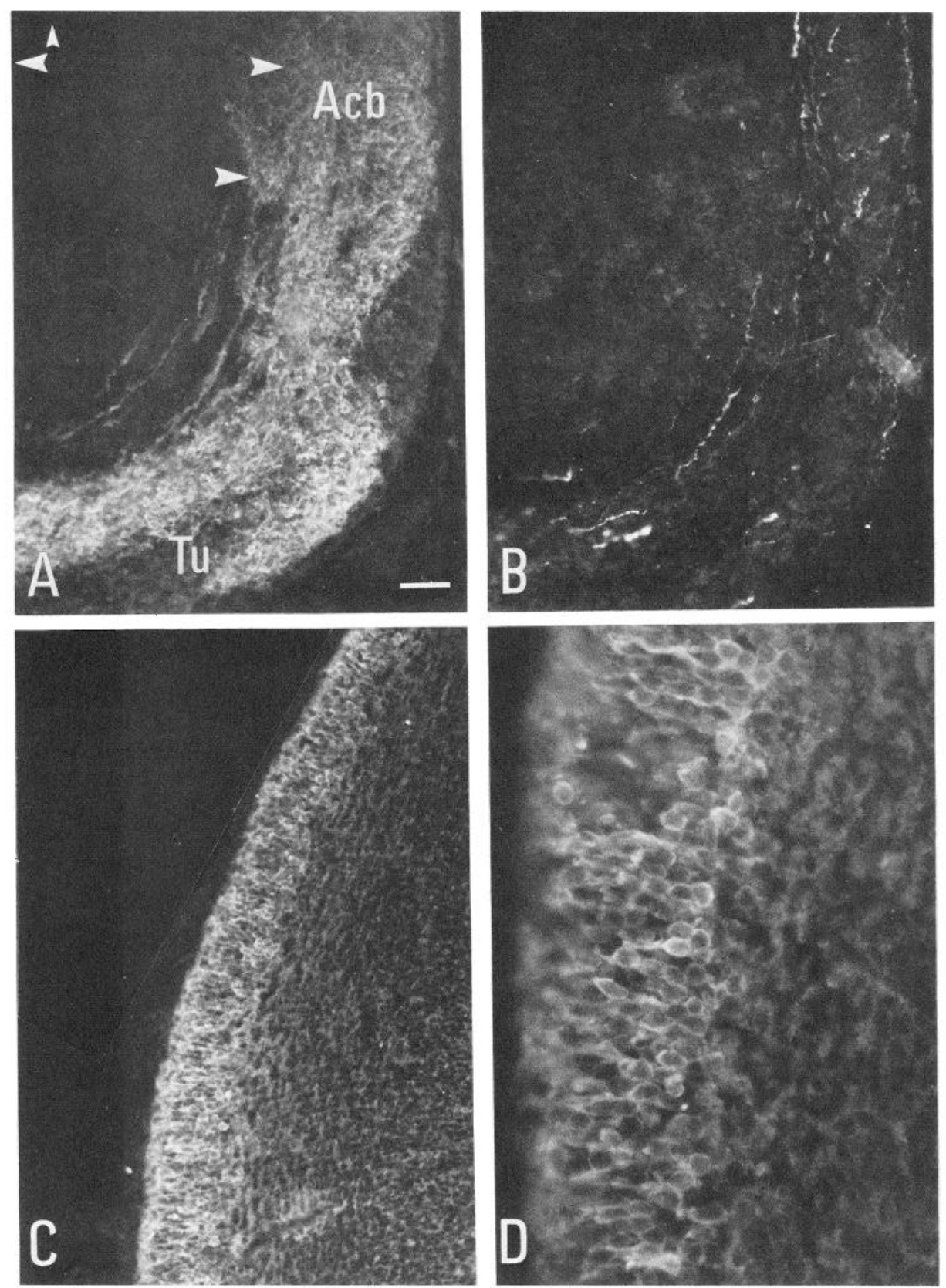

Figure 9. Immunofluorescence photomicrographs of DARPP-32-LI $(A, C$, $D)$ and TH-LI $(B)$ in the nucleus accumbens $(A c b)$, olfactory tubercle $(T u)$ $(A, B)$, and olfactory bulb $(C, D)$ of the embryonic $18 \mathrm{~d}(A, B), 19 \mathrm{~d}(C)$, and newborn $(D)$ rat. $A, B$, Densely packed DARPP-32-positive cells are exhibited in the $A c b$ and $T u$ on day 18 of gestation $(A)$, but the innervation of these regions by TH-containing fibers, shown in an adjacent section $(B)$, is sparse or nonexistent. $C, D$, Weakly stained DARPP32 -immunoreactive neurons are visible in the frontoparietal cortex on day 16 , and are no longer restricted to the outermost layer as at day 14. The neurons send out short, radial processes, directed both apically and basally $(D)$. Processes extending from these cells into the external plexiform layer can be seen Small arrowhead in upper left corner of $A$ points dorsally, the large one medially. Scale bar, $50 \mu \mathrm{m}$ in $A-C, 20 \mu \mathrm{m}$ in $D$. with short, randomly oriented processes (Fig. 1, D, E). These cells were restricted to the most ventrolateral part of the caudate and numbered approximately $1-3$ per $14 \mu \mathrm{m}$ section. At the same gestational age, no TH-immunoreactive fibers could be detected in any of these 3 areas, although a few cells (not illustrated) in the primary olfactory cortex, ventral to the DARPP32-positive neurons, and a sparse collection of axons in the medial forebrain bundle, were visible (Fig. 1, $D-F$ ).

\section{Day 15 of gestation $(C R L=14 \mathrm{~mm})$ (Fig. 3)}

Six embryos from 2 mothers were used. DARPP-32-immunoreactive cells were more numerous both in the cortical areas and in the caudate nucleus. The DARPP-32-positive cells in the rostral part of the frontal cortex can now be classified into 3 distinct groups, comprising a densely packed clump near the lateral olfactory tract, a less dense group in the frontoparietal cortex, and then individual cells from the frontoparietal cortex through the cingulate cortex, along the most medial aspects of the hemisphere to the anlage of the olfactory tubercle (Fig. 3, $A-D$ ). More caudally, the immunoreactive cells in the frontoparietal cortex and the cingulate cortex became progressively scarcer, such that they were almost extinct at the level of the medial habenula, whereas a few immunoreactive cells could still be detected even at the most caudal part of the developing primary olfactory cortex.

A greater number of more intensely immunofluorescent DARPP-32-positive somata were now apparent in the ventrolateral caudate nucleus of the 15-d-old embryo (Fig. 3, B, C). Fibers containing DARPP-32-LI could be seen, and these were also confined to the ventrolateral region of the caudate nucleus (Fig. 3, B, C). No DARPP-32-immunoreactive fibers were seen elsewhere in the brain. 


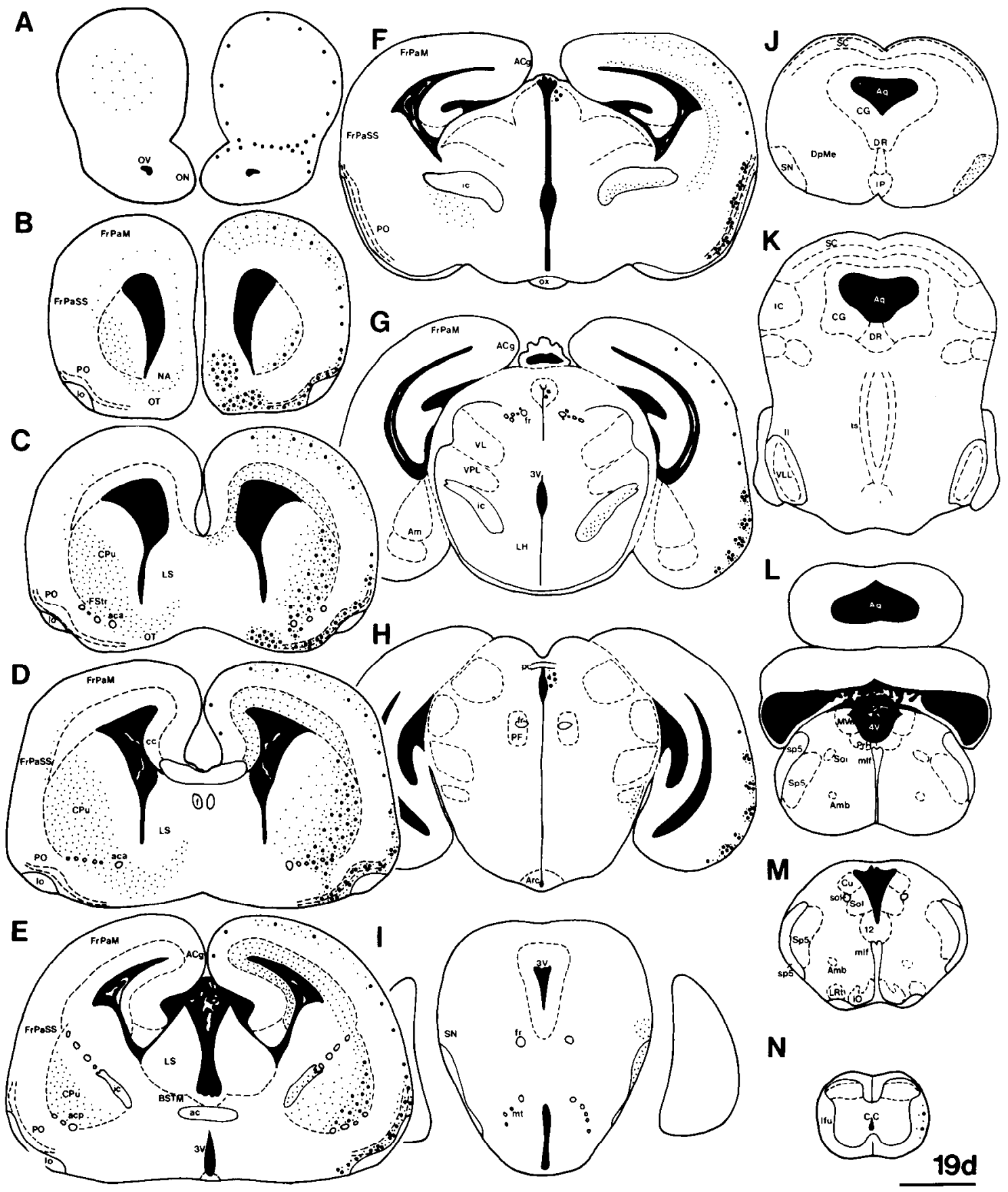

Figure 10. Diagrams of frontal sections at various levels through the rat brain on day 19 of gestation. Large dots indicate 3-5 DARPP-32immunoreactive cell bodies in a $14 \mu \mathrm{m}$ section. Small dots on the right-hand side are related to the density of DARPP-32-positive fibers, while the small dots on the left-hand side indicate the density of ' $\mathrm{TH}$-immunoreactive innervation. The latter symbols have only been used where relevant, but refer to the same side of the brain section as the DARPP-32 dots. Abbreviations are listed in the text.

TH-positive fibers were more prominent in the medial forebrain bundle, but could still not be identified in either the frontal cortex or the caudate nucleus (Fig. 3, D, E). A few axonal processes were visible, however, in the primary olfactory cortex (Fig. 3C).

\section{Day 16 of gestation $(C R L=15 \mathrm{~mm}$ ) (Fig. 4)}

Six embryos were studied. DARPP-32-immunoreactive cells were now deeper in the frontal cortex and were also present in the primary olfactory cortex around the lateral olfactory tract, the rostral frontoparietal and the presumptive cingulate cortex (Figs. 4, $A-D$, and $5 A$ ). In addition to the DARPP-32-positive cells in the frontoparietal cortex, some weakly staining fibers were now becoming visible, while in the primary olfactory cortex there was a moderately dense network of strongly fluorescent DARPP-32-immunoreactive axons (Fig. $6 A$ ). A few fibcrs containing DARPP-32-LI had apparently fasciculated at the outermost tip of the subcortical white matter (Fig. 6A), but could not at this stage be traced any further towards the midline. The DARPP-32-positive cells and their processes throughout the 

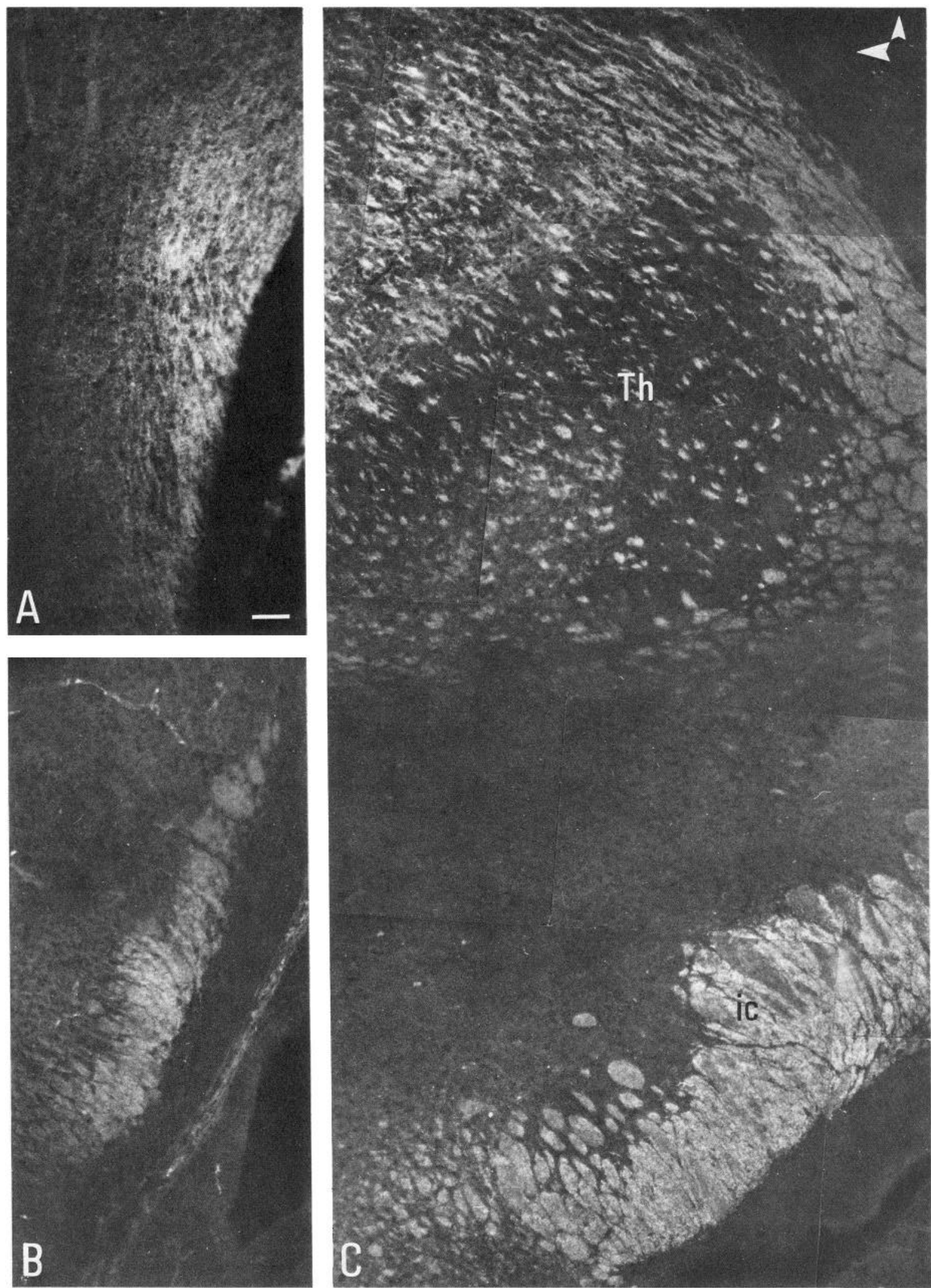

Figure 11. Immunofluorescence photomicrographs of DARPP-32-immunoreactive fibers in the internal capsule on days $19(A)$ and $21(B)$ of gestation, and in the internal capsule and thalamus $(T h)$ of the newborn rat $(C)$. Processes in the internal capsule, first displayed at day 16 , increase rapidly in number on days $19(A)$ and $21(B)$, and at birth the appearance of the DARPP-32-positive fibers is similar to that seen in the adult. In the newborn, the fibers in the internal capsule are strongly immunoreactive to DARPP-32. Dorsal and slightly medial to the internal capsule, in a region including the ventrolateral thalamus $(T h)$, a group of fibers is visible. Small arrowhead in upper right corner of $C$ points dorsally, big arrowhead medially. Scale bar, $50 \mu \mathrm{m}$. Magnification is the same for all micrographs. 

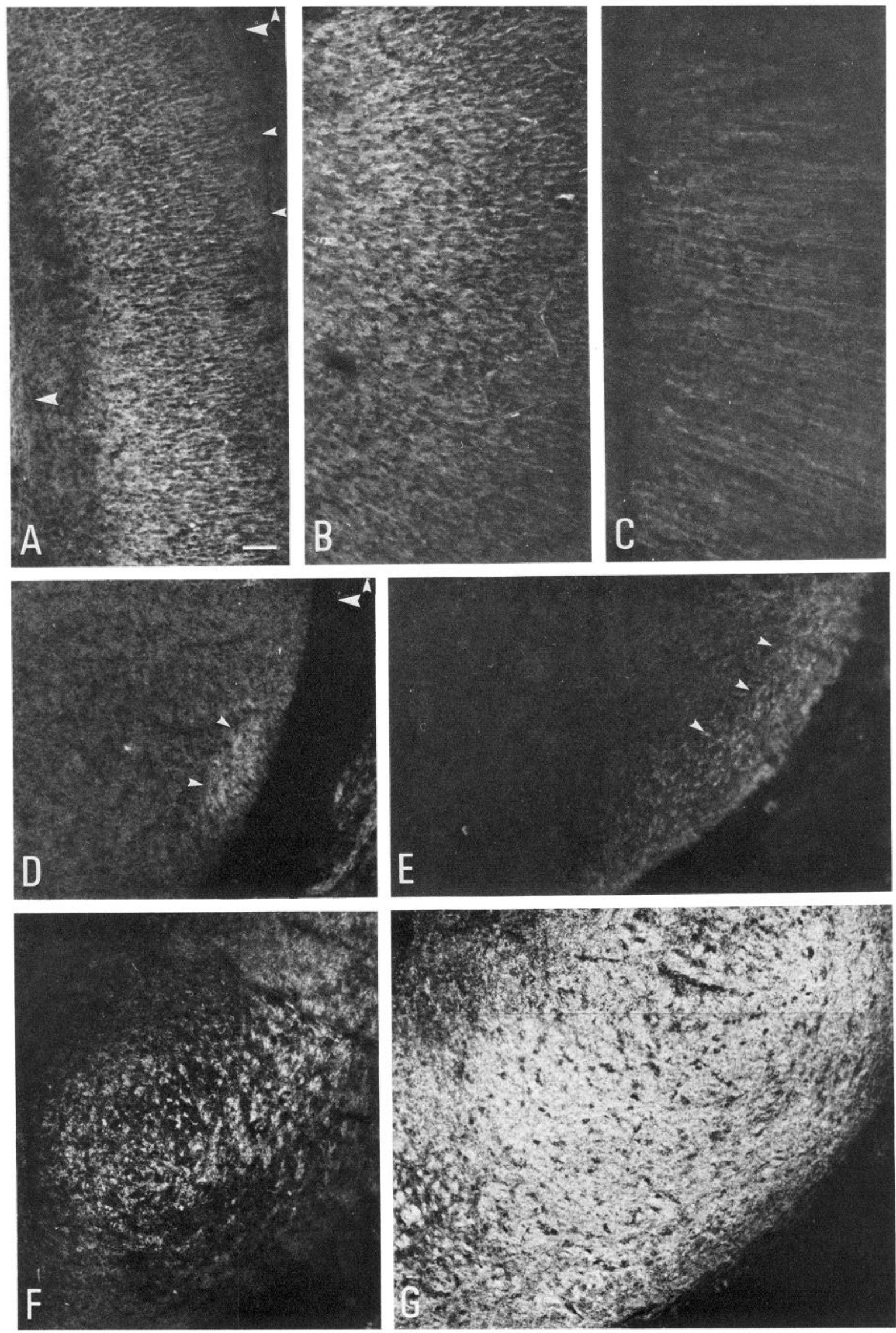


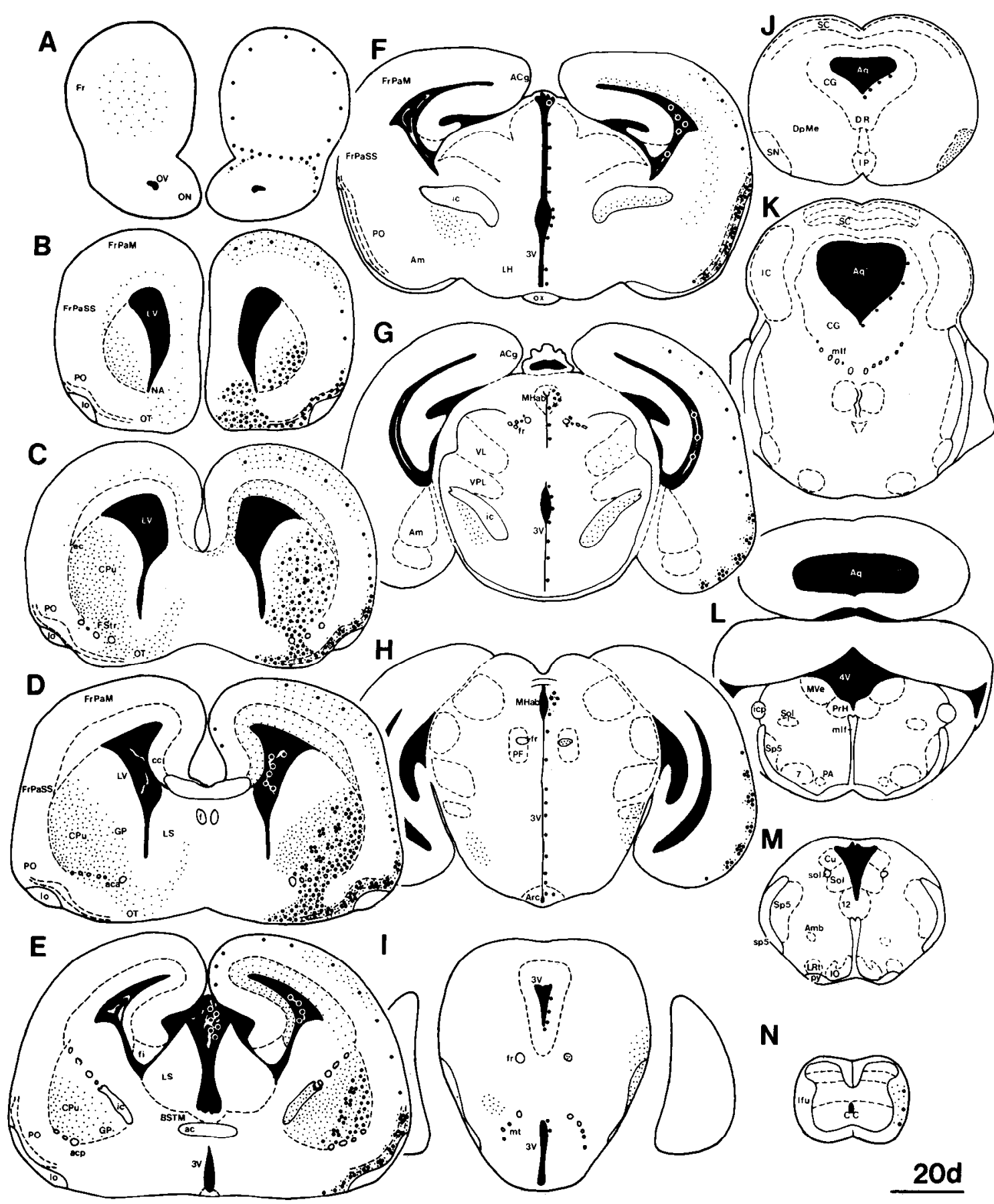

Figure 12. Diagrams of frontal sections at various levels through the rat brain on day 20 of gestation. Large dots indicate 3-5 DARPP-32immunoreactive cell bodies in a $14 \mu \mathrm{m}$ section. Small dots on the right-hand side are related to the density of DARPP-32-positive fibers, while the small dots on the left-hand side indicate the density of TH-immunoreactive innervation. The latter symbols have only been used where relevant, but refer to the same side of the brain section as the DARPP-32 dots. Abbreviations are listed in the text.

Figure 13. Immunofluorescence photomicrographs of DARPP-32-LI in the forebrain of the embryonic $20 \mathrm{~d}(A), 21 \mathrm{~d}(B)$ and newborn $(C)$ rat and in the substantia nigra of the embryonic $18 \mathrm{~d}(D), 19 \mathrm{~d}(E), 20 \mathrm{~d}(F)$, and newborn $(G)$ rat. $A-C$, With increasing age, the number of DARPP32-immunoreactive neurons in the frontal cortex decreases, as is illustrated in micrographs $A-C$. They still remain at the day of birth, but they have now apparently migrated inwards and display radially arranged processes which ultimately extend to all cortical layers. $D-G$, DARPP-32-LI in the substantia nigra (arrowheads) is initially seen on day $18(D)$, approximately $2 \mathrm{~d}$ after its appearance in the internal capsule. The density and extent of the DARPP-32-positive processes increase on days $19(E$, arrowheads) and $20(F)$ of gestation, and by the day of birth $(G)$, their disposition is the same as in the adult rat. Small arrowheads in upper right corner of $A$ and $D$ point dorsally, big arrowheads medially. Bar, $50 \mu \mathrm{m}$. Magnification is the same for all micrographs. 

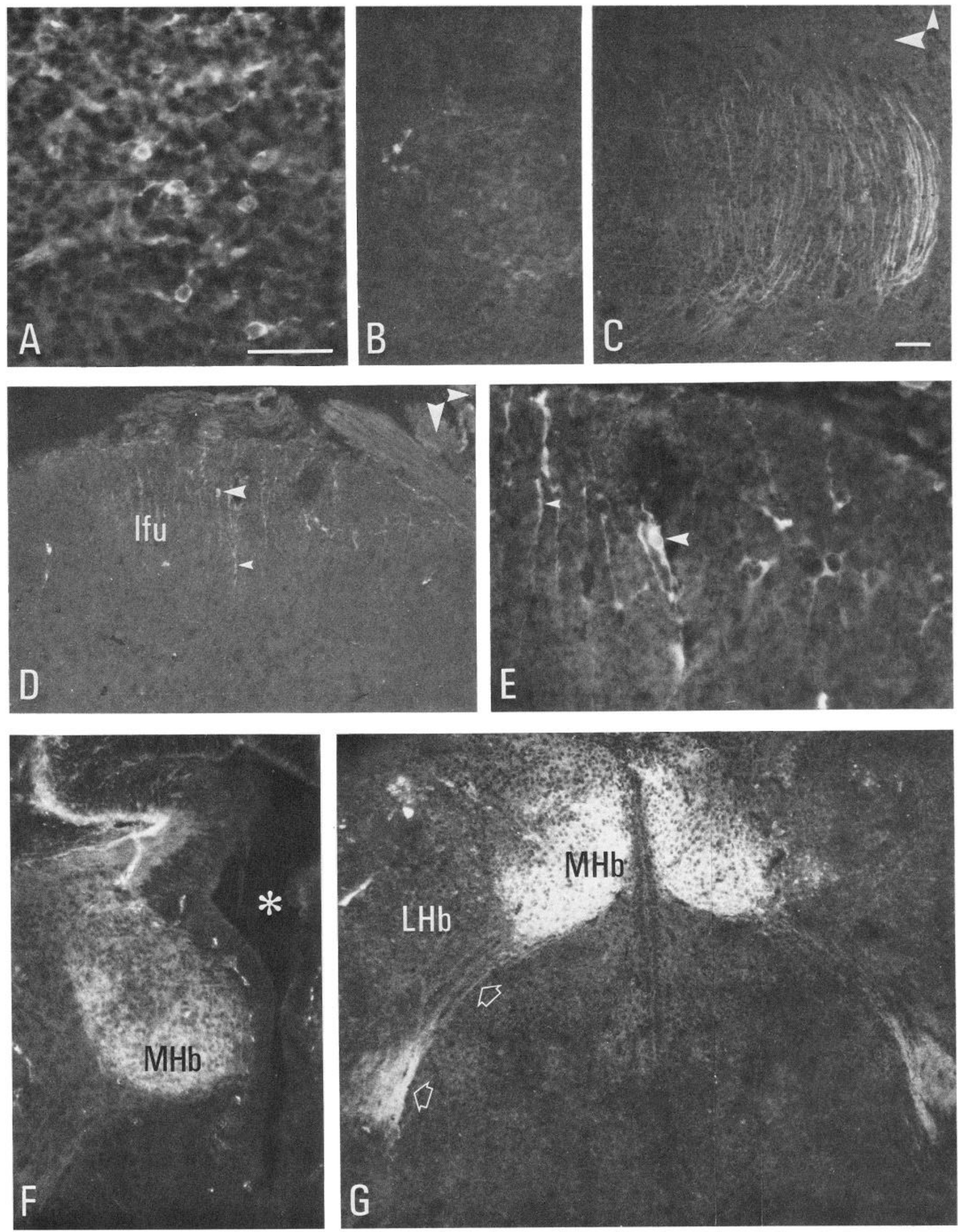
rostral olfactory tubercle were densely distributed (Fig. 5A). The position of the islands of Calleja, however, was as yet indeterminate.

The number of DARPP-32-immunoreactive cells in the most ventrolateral part of the caudate nucleus continued to increase by gestational day 16 (Figs. $4, B-D$, and $5 A$ ). In addition, fibers that appeared to emanate from these cells could be seen within the caudate, but did not extend into the subependymal proliferative zone to the lateral ventricle (Fig. $5 A$ ). These DARPP32-positive fibers coursed caudally from the striatum and into the internal capsule, where they were seen for the first time at this age (Fig. 4E). The fibcrs did not extend as far as the substantia nigra, however.

Many TH-positive fibers were now seen in the ventrolateral part of the caudate nucleus, intermingling with the DARPP-32immunoreactive structures (Fig. 4, $B-D$ ). In addition, a few THcontaining processes were located in the olfactory tubercle (Fig. $5 B$ ). The distinct ascending dopamine tract could be followed in the medial forebrain bundle (Fig. 4, $F, G$ ) joining the ventral aspects of the internal capsule (Fig. $4 E$ ).

\section{Day 17 of gestation $(\mathrm{CRL}=17 \mathrm{~mm})(\mathrm{Fig} .7)$}

The immunoreactive cells in the primary olfactory cortex of the five 17-d-old fetuses examined appeared to have undergone a slight reorganization; they were no longer evenly distributed within the primary olfactory cortex, near the lateral olfactory tract, but were now clumped together in groups of 5-7 cells (Fig. $6 B$ ). The fibers from these neurons, however, maintained a relatively homogeneous disposition. The number of cells containing DARPP-32-LI in the striatum, olfactory tubercle, and primary olfactory cortex increased further at this stage of gestation, whereas those immunopositive neurons in the frontoparietal cortex were less densely packed (Fig. 7, $A-H$ ).

The TH-positive fibers were organized similarly to those at day 16 and still occupied a ventrolateral position overlapping the DARPP-32-immunoreactive structures (Fig. 7, $B-F$ ).

\section{Day 18 of gestation ( $C R L=22 \mathrm{~mm}$ ) (Fig. 8)}

Six fetuses were studied. The DARPP-32-immunoreactive fibers in the primary olfactory cortex remained quite weakly stained and sparsely distributed at this age, whereas those in the caudate extended in a dense meshwork as far as the proliferative zone near the lateral ventricle (Fig. 8C). DARPP-32positive processes increased in density in the internal capsule, appeared for the first time in the substantia nigra (Fig. $8 D$ ), and were demonstrable in the olfactory tubercle, also for the first time, at gestational day 18 (Fig. 8, $B, C$ ).

DARPP-32-immunoreactive neurons were prominent in 2 more areas of the fetal rat brain at day 18 of gestation. For the first time, cells and fibers were visible in what could be delineated as the nucleus accumbens (Fig. 9A). These cells had pre- sumably migrated from the medial areas, where DARPP-32immunoreactive cells had been visualized at earlier stages of gestation (Fig. 5A). DARPP-32-positive cells also became visible in the fundus striati, forming a bridge between the densely packed neurons of the ventral caudate nucleus and those of the olfactory tubercle (Fig. $8 \mathrm{C}$ ).

At this stage, TH-positive fibers were also apparent in the nucleus accumbens area, but they were sparsely distributed compared to the number of DARPP-32 cells (Fig. 9B). Furthermore, even though DARPP-32-LI had increased in the olfactory tubercle, the number of TH-positive fibers was still scarce. For the first time TH-positive fibers were seen in the frontal cortex, but they did not exhibit an overlapping distribution with the DARPP-32-positive cells (Fig. $8 A$ ).

\section{Day 19 of gestation (CRL $=27 \mathrm{~mm}$ ) (Fig. 10)}

Five animals from 2 mothers were examined. The number and fluorescent intensity of DARPP-32-positive celis increased in several of the major groupings previously described, namely, the primary olfactory cortex [where they had adopted sharply delineated clusters (Fig. 6C)], caudate, nucleus accumbens, fundus striati, and olfactory tubercle (Fig. 10, $B-E$ ). In contrast, there was a decline in cell numbers and staining intensity in cortical areas, but this decline was least pronounced in the dorsolateral region. Instead, the number of DARPP-32-positive fibers increased in these regions, particularly in the frontoparietal cortex, where a very dense group of radially oriented processes was apparent (Fig. 10, $B, C$ ). In other arcas of the frontal cortex, the radial alignment was not so clear, and more commonly the fibers appeared to be randomly arranged. The DARPP32-immunoreactive fibers in the corpus callosum and subcortical white matter could now be seen extending into the cingulate cortex (Fig. 10, $C-E$ ). DARPP-32-positive fibers could also be followed caudally from the striatum along the densely packed tracts in the presumptive internal capsule (Fig. 11A) to the substantia nigra, where a substantial innervation was now visible (Fig. 12E). In the lateral olfactory nucleus, neurons containing weak DARPP-32-LI were displayed for the first time (Fig. 9C). A sparse network of DARPP-32-immunoreactive structures was first apparent in the medial habenula at day 19 of gestation (Fig. $10, F-H$ ), and extremely weakly staining cell bodies and processes could just be detected in the lateral funiculus of the cervical spinal cord (Fig. 10N).

The distribution of TH-positive fibers was more extensive, compared to that on day 18 , but qualitatively similar. THpositive fibers were, however, detected for the first time in the deep layers of the neocortex (Fig. 10, $B-D$ ).

Day 20 of gestation $(C R L=32 \mathrm{~mm})$ (Fig. 13)

Six fetuses were examined. DARPP-32-containing cell somata were now located in the deep layers of the frontoparietal cortex

Figure 14. Immunofluorescence photomicrographs of DARPP-32-LI in various parts of the developing central nervous system of the rat. $A$, Arcuate nucleus displays DARPP-32-containing cell bodies and short processes on day 20 of gestation. $B, C$, In the central amygdaloid nucleus $(B)$ and the ventral tegmental area $(C)$, DARPP-32-positive structures are first seen in the newborn rat. $D, E$, In the lateral funiculus (Ifu) of the spinal cord, a few weakly staining DARPP-32-positive soma are first visible on day 19 of gestation, and, by the next day, they extend throughout the funiculus (big arrowhead points to ccll body, the small one to a proccss) (D). On day 21 , the cells (big arrowhead) are strongly immunopositive and exhibit predominantly radially oriented processes (small arrowhead), which extend from the outer ependymal layer to the gray matter of the spinal cord $(E) . F, G$, A dense plexus of positive fibers is seen in the medial habenula $(M H b)$ on day 21 of gestation $(F)$. On the day of birth, the fiber density has increased, and fibers can be seen to run from the medial habenula into the fasciculus retroflexus (open arrows in $G)$. LHb $=$ lateral habenular nucleus. Asterisk in $F$ indicates third ventricle. Small arrowheads in upper right corner of $C$ and $D$ point dorsally and large arrowheads medially. Bar, $50 \mu \mathrm{m}$. $A$ and $E$ have the same magnification, and $B, C, D, F$, and $G$ have the same magnification. 


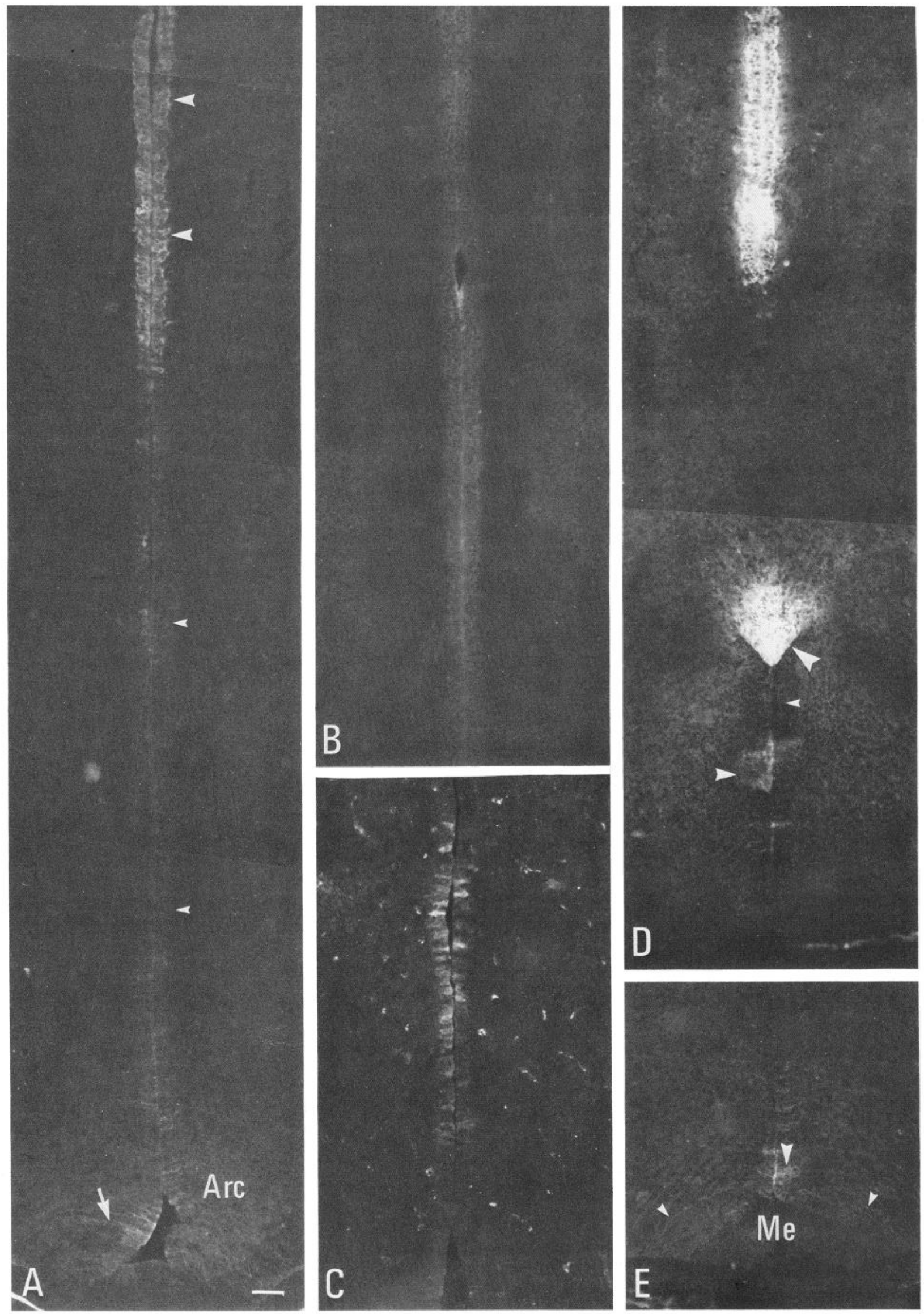

Figure 15. Immunofluorescence photomicrographs of DARPP-32-LI along the third ventricle of the developing rat brain. B, Part of adjacent section to $A$ incubated with control serum. $A$, Almost the full length of the third ventricle of the newborn rat, demonstrating immunoreactive 

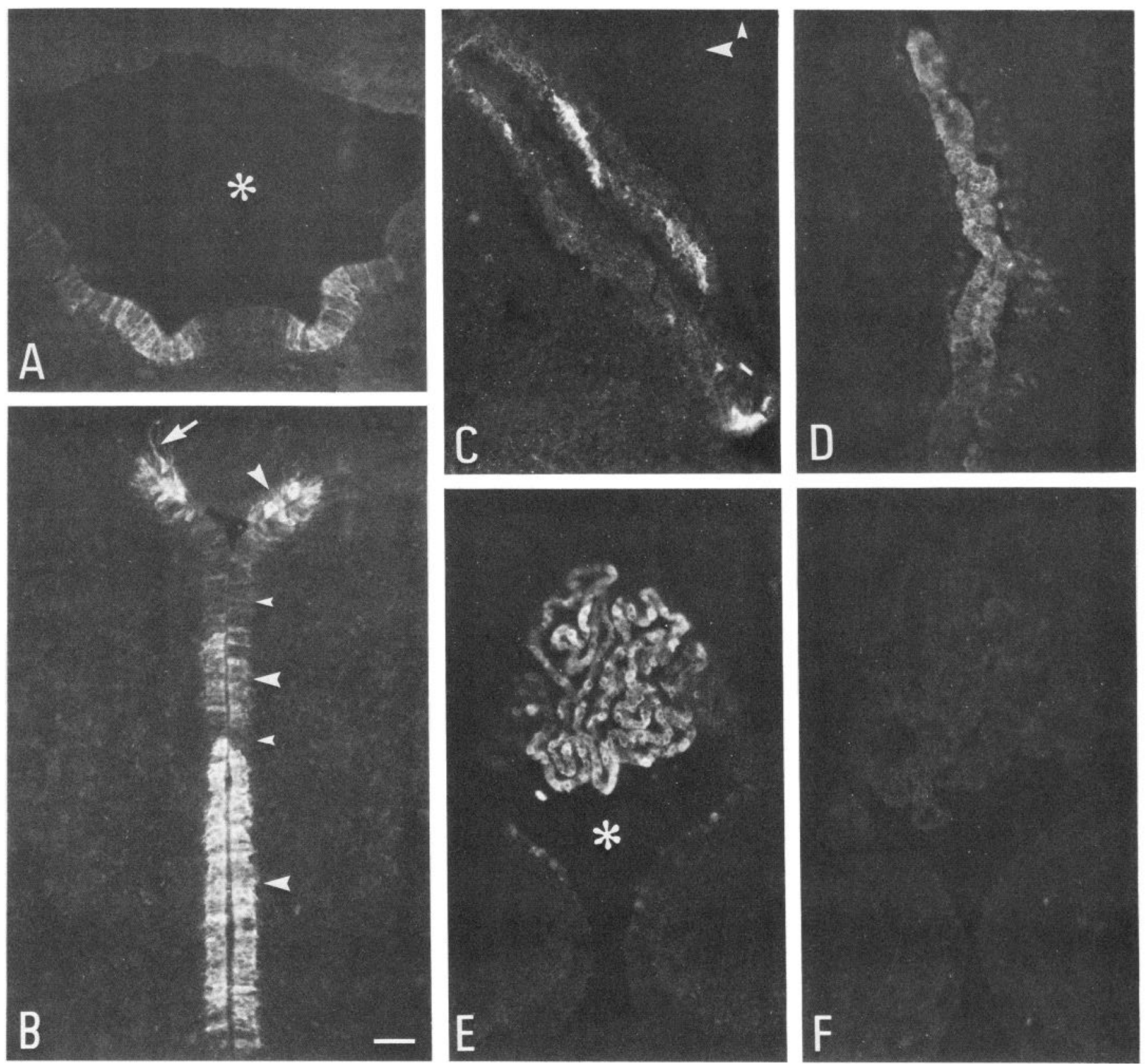

Figure 16. Immunofluorescence photomicrographs of DARPP-32-immunoreactive structures around the Sylvian aqueduct $(A, B)$, the lateral $(C$, $D)$ and the third $(E)$ ventricle. $F$, Adjacent section to $E$, incubated with control serum. $A, D$, Immunoreactive somata are first seen on day 20 in ependymal cells around the Sylvian aqueduct, exhibiting bilateral symmetry $(A)$. On the day of birth, the cells are more brightly fluorescent and still exhibit lateral symmetry. Fibers extending from the ependymal cells into the neuropil are visible (arrow in $B$ ). Note bilateral symmetry exhibited by clearly immunoreactive (big arrowheads) and DARPP-negative cells (small arrowheads). DARPP-32-LI appears for the first time on day 21 of gestation in the choroid plexus of the lateral ventricle with a few scattered, but intensely fluorescent, cell bodies $(C)$. On the day of birth, many more positive cells are visible, but they are more diffusely stained $(D)$. DARPP-32-immunoreactive cell bodies are also displayed in the choroid plexus of the third ventricle (asterisk) in the newborn rat $(E)$. No fluorescence can be seen in the section incubated with control serum $(F)$. Small arrowhead in upper right corner of $C$ points dorsally and large arrowhead medially. Bar, $50 \mu \mathrm{m}$. All micrographs have the same magnification.

$\leftarrow$

somata in the ependymal cell layer. Note the bilateral symmetry of the DARPP-32-positive cell bodies and that only the dorsal ependymal cells are stained (big arrowheads), whereas the lower two-thirds appear DARPP-32-negative (small arrowheads). Ependymal cells close to the arcuate nucleus appear weakly DARPP-32-positive (arrow). No positive ependymal cells can be seen after incubation with control serum $(B)$. $(C)$ Immunopositive somata appear heterogenously distributed along the length of the third ventricle on day 20 of gestation. Bilateral symmetry is already indicated at this stage, but appears very pronounced at birth $(D)$. $D$, Third ventricle at posterior level separated in a dorsal part, completely outlined by DARPP-32-positive cell bodies, and a ventral part, where the dorsal cells are strongly fluorescent with dorsally radiating processes (big arrowhead). More ventrally located ependymal cells exhibit weak DARPP-32-LI (medium-sized arrowhead) with symmetry, whereas other ependymal cells seem to lack immunoreactivity (small arrowhead). E. In the newborn rat, ependymal cells close to the arcuate nucleus are DARPP-32-positive (big arrowhead), with processes radiating in a lateroventral direction (small arrowheads). Arc, arcuate nucleus; $M e$, median eminence. Scale bar, $50 \mu \mathrm{m}$. All micrographs have the same magnification. 


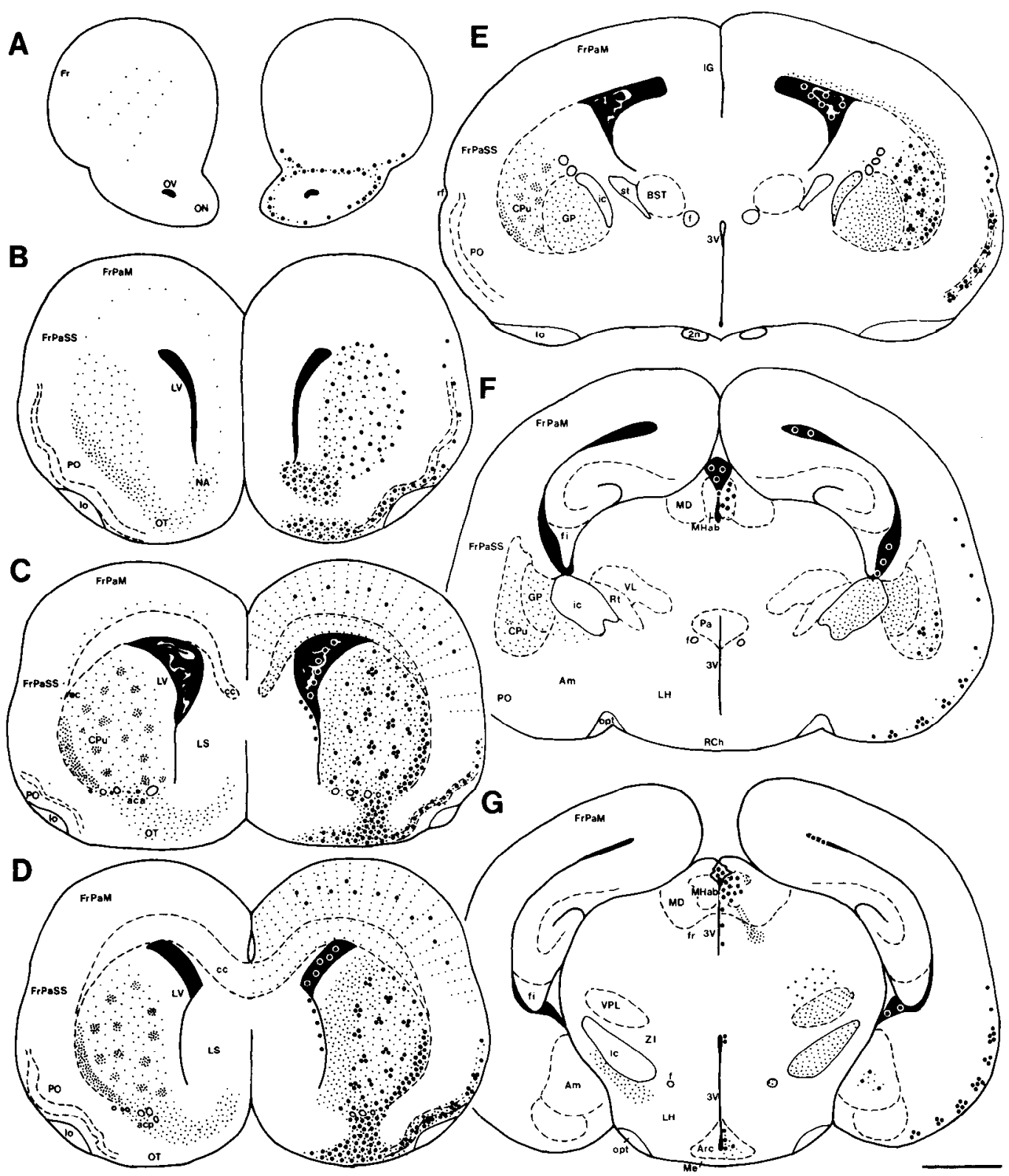

Figure 17. Diagrams of frontal sections at various levels through the rat brain on the day of birth. Large dots indicate 3-5 DARPP-32-immunoreactive cell bodies in a $14 \mu \mathrm{m}$ section. Small dots on the right-hand side are related to the density of DARPP-32-positive fibers, while the small

(Fig. 12A). In the caudate nucleus, the disposition of DARPP32-positive cells had changed, such that, in a manner similar to that observed in the primary olfactory cortex, they were now aggregated into about 8 clusters per section, each containing between 5 and 10 cells (Figs. $6 D ; 13, D, E$ ). The area immediately surrounding these clumps of neurons, which were distributed throughout the whole of the caudate, contained far fewer neurons. In addition to these cell groups, a band, 6-8 cells thick, of neurons containing DARPP-32-LI was visible along the ventrolateral rim of the caudate (Figs. $6 D ; 13, D, E$ ). Their distribution, however, was quite homogeneous.

Analysis of the innervation of the caudate by $\mathrm{TH}$-containing processes in adjacent sections revealed that in 1 or 2 of the DARPP-32-containing cell clusters there was also a slightly enhanced density of TH-positive fibers, particularly around the ventrolateral edge of the caudate (Fig. $6 E$ ). However, no increased TH fiber density was observed in the majority of the DARPP-32-positive cell clusters, and in general the distribution of TH-immunoreactive fibers was even throughout the caudate nucleus.

DARPP-32-positive fiber networks and cell bodies were found in several more areas on gestational day 20 . For example, the globus pallidus, which could now be identified as an entity separate from the caudate, was innervated by DARPP-32-positive processes (Fig. 13, D, E). In the arcuate nucleus (Fig. 14A), occasional DARPP-32-immunoreactive cell bodics and processes had become visible by this time. In the medial aspects of the habenular complex, numerous DARPP-32-immunoreactive cells were now seen (Fig. 13, $G, H$ ), and a very dense plexus of DARPP-32 processes was apparent in the substantia nigra 

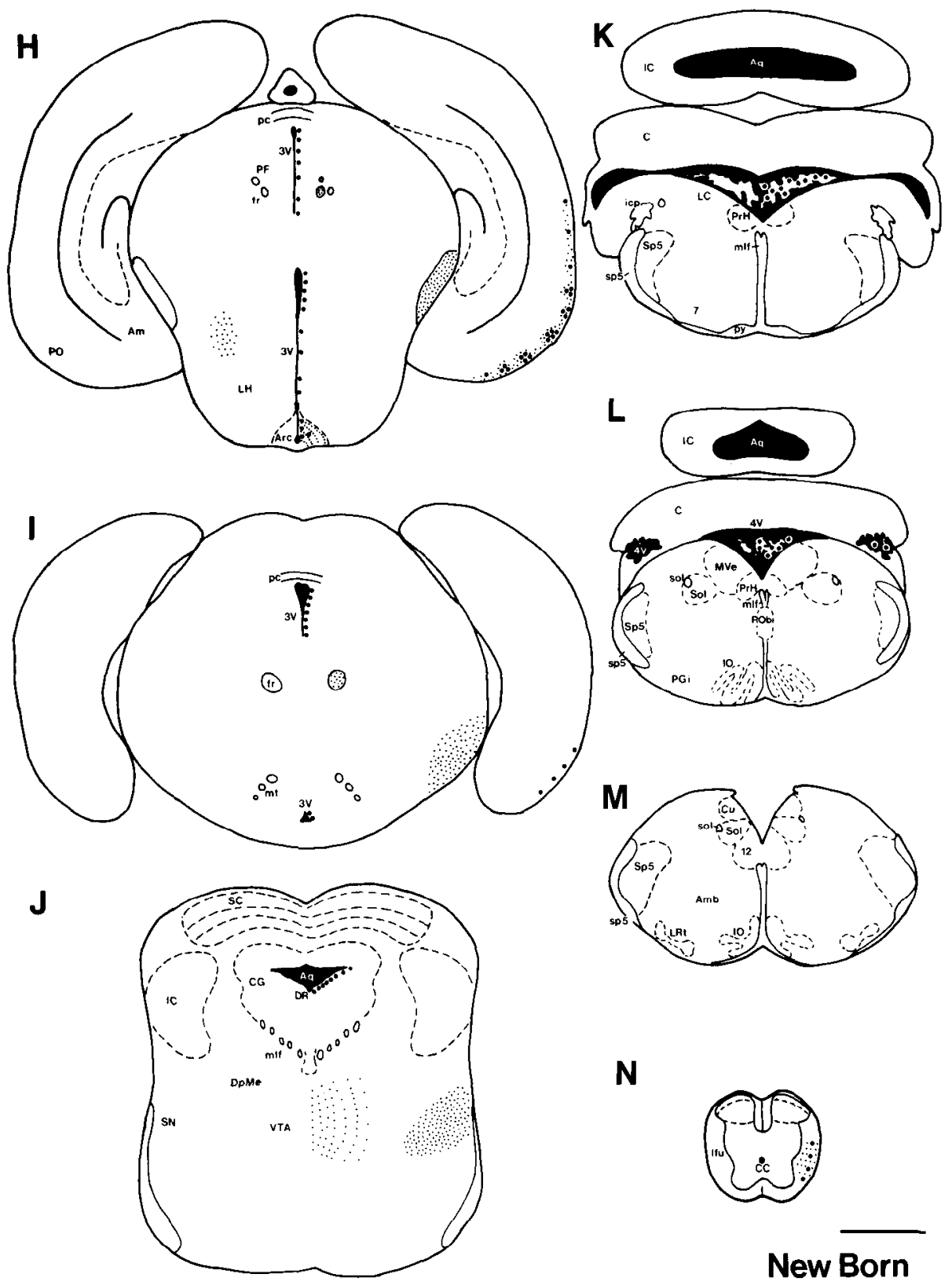

dots on the left-hand side indicate the density of TH-immunoreactive innervation. The latter symbols have only been used where relevant, but refer to the same side of the brain section as the DARPP-32 dots. Abbreviations are listed in the text.

(Fig. 12F). It was also possible to discern DARPP-32-positive cells and fibers in the lateral funiculus of the spinal cord (Fig. $14 D$ ).

Some cell somata and short processes in the ependymal layer of the third ventricle (Figs. 13, F-H; 15C) and around the Sylvian aqueduct (Figs. 13, $I, J ; 16 A$ ) were immunopositive. Not all the ependymal cells were so stained, but, nevertheless, a distinct, bilaterally symmetrical pattern could be perceived. The immunoreactive cells in the ependymal layers were most prominent in the middle part of the caudal third ventricle at this stage (Fig. 15C). DARPP-32-positive cells could also be detected in the choroid plexus of the third and lateral ventricles, but, again, not all the cells in these regions were immunoreactive.

No TH-immunoreactive fibers specifically innervating the cells of the ependymal layer of the third ventricle could be detected, although a few occasional processes terminating near the subependymal zone of the ventral Sylvian aqueduct could be discerned.

\section{Day 21 of gestation $(C R L=37 \mathrm{~mm})$}

Five fetuses were studied. More DARPP-32-positive neurons were observed in the lateral anterior olfactory nucleus. Fibers in the frontal cortex continued to extend radially to its outer layer (Fig. 12B). DARPP-32-immunoreactive fibers could also be visualized in the anterior commissure and the corpus callosum. Very densely bundled axons coursed through the internal capsule (Fig. $11 B$ ) to the substantia nigra.

The medial aspect of the habenula was densely packed with 

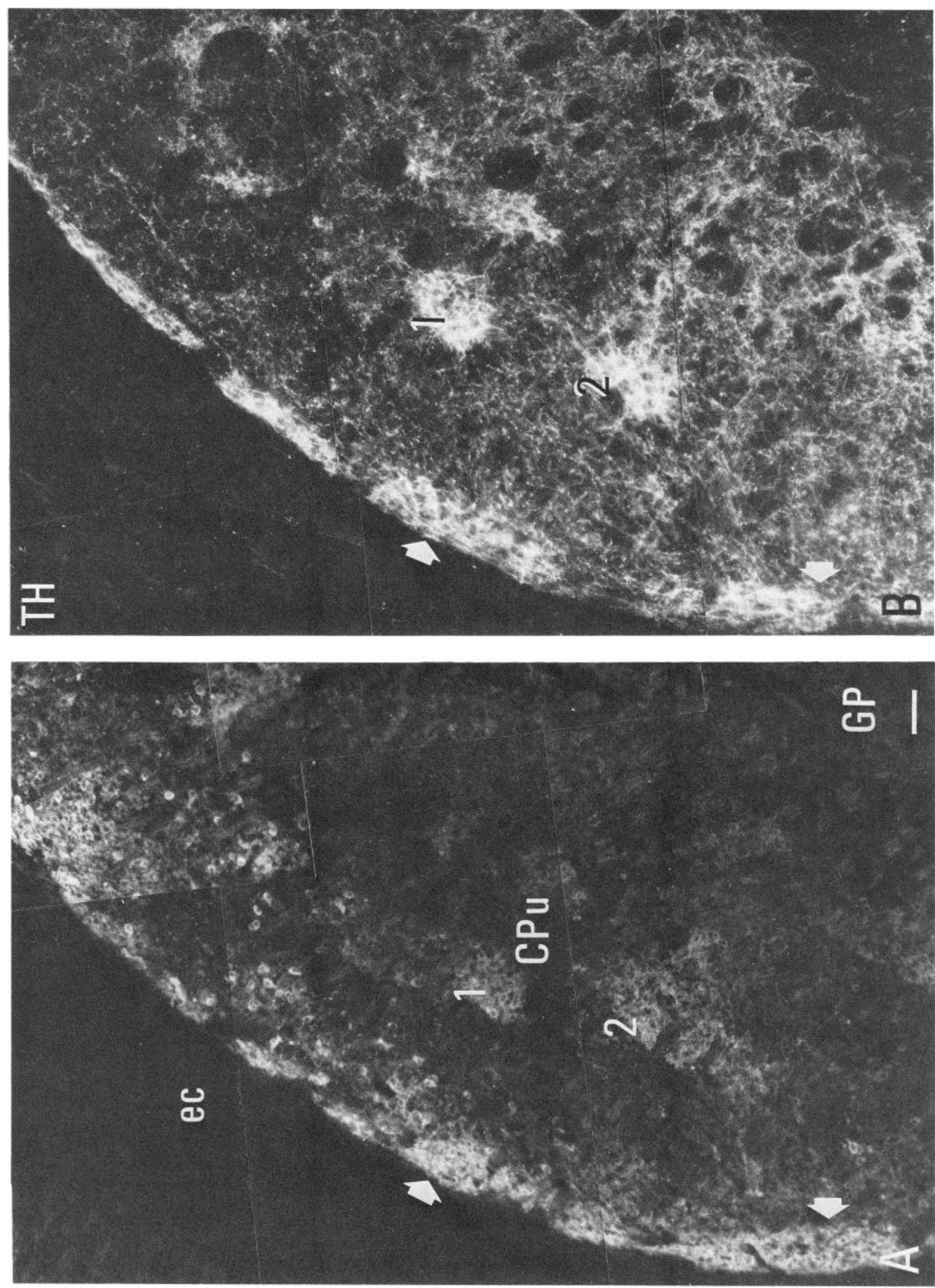

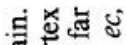

要

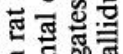

E

ơ

을

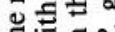

돈용

䇃

刃낭

노원

전

政

준

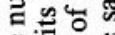

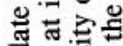

告

ฮี.

高告

5 路

以N

的

已⿹

范

. ज्ञ

चु एᄃ

픙

ब전

전전

政声

1 .

敦焉

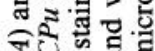

응혀

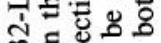

둘

考 进

a 80

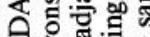

tน

品三

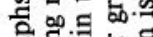

견

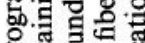

돈.

ह

ㅇํㅇํํำ

टू่ त

8

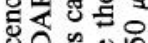

还论

넝

ิํํํำ

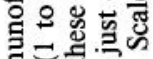

हn

w

$\infty$ 릉 है है

的高

s. 
DARPP-32-positive cell bodies (Fig. 14F), and these appeared to be connected to the fasciculus retroflexus.

The DARPP-32-immunoreactive cells in the lateral funiculus of the spinal cord had also increased in number, were more intensely stained, and displayed more extensive processes, which coursed inwards in a radial direction as far as the gray matter (Fig. 14E).

More cells in the choroid plexus of the lateral (Fig. 16B) third and fourth ventricles became DARPP-32-immunoreactive.

\section{Day of birth (Fig. 17)}

Eight animals were investigated. DARPP-32-positive cells in all areas of the CNS continued to proliferate and/or undergo migration.

Cells in the frontoparietal cortices by now appeared in the midlayers, while their processes extended with a typically radial orientation throughout the full depth of the cortex (Figs. $12 C$; $7, C, D$ ). Fibers in the primary olfactory cortex, on the other hand, continued to display an apparently random disposition. The cingulate cortex no longer exhibited as many prominent DARPP-32-immunoreactive cell bodies because of a generalized weakening of the level of immunoreactivity in this region.

The clusters of cells in the caudate nucleus were similar in number to those found on days 20 and 21 of gestation but now covered almost the entire nucleus (Figs. 17, $C-E, 18 A, 19 A$ ), except for a thin periventricular zone. Scrutiny of adjacent sections stained for TH-LI demonstrated that the fiber innervation originating from the substantia nigra was also present in such clusters (Fig. 17, $C-E$ ), and that the areas of higher-density TH innervation coincided with those of the DARPP-32-positive cell aggregates (cf. Fig. 18, $B$ and $A$ ).

The descending striatonigral fiber bundles in the internal capsule (Fig. 11C) achieved a disposition similar to that in the mature animal. In addition, a new set of DARPP-32-positive fibers was discovered on the day of birth in the thalamus. This dense network of fibers was organized in a principally dorsomedial orientation (Fig. 11C).

In the central amygdaloid nucleus, DARPP-32-containing somata, with short axonal processes, could be initially identified at this time (Fig. 17G). An example of one of these cells is shown in Figure 14B. Individual TH-positive fibers were first detectable near the amygdaloid complex on day 21 of gestation, but they were lateral to the DARPP-32-immunoreactive cells of the central amygdaloid nucleus itself. A moderately dense meshwork of DARPP-32-immunoreactive axons was first seen in the ventral tegmental area (Fig. 14C).

The density of fiber networks in the substantia nigra (Fig. $9 G$ ), medial habenula and fasciculus retroflexus (Fig. 14G), and globus pallidus on the day of birth was similar to that observed in the adult. In fact, in some sections at the level of the dorsal thalamus, it was possible to trace the weakly DARPP-32-staining fasciculus retroflexus from the medial habenula (Fig. 14G).

Intensely staining ependymal cells inhabited the dorsal, middle, and ventral aspects of the third ventricle (Fig. 15, $A, D$ ). In the arcuate nucleus, long and distinct, but weakly fluorescent processes could be seen running in a ventrolateral direction from the ependymal layer (Fig. 15, $A, E$ ). DARPP-32-immunoreactive cells appeared for the first time in the ependymal layer along the lateral ventricle. It is noteworthy that they were confined entirely to the medial side of the ventricle; the lateral ependyma of the lateral ventricle contained DARPP-32-positive fibers of the striatum, but not cell somata. In the ependyma of the Sylvian aqueduct, the DARPP-32-LI was stronger, and immunoreactive somata were now found along the whole of the ventral ependymal layer (Fig. 16, $A, B$ ), in places $2-3$ cells thick. Processes could be seen coursing into the dorsal mesencephalon (Fig. 16B). Many DARPP-32-positive cells were still seen in the choroid plexus of the third (Fig. 16E), lateral (Fig. 16C), and fourth ventricles.

\section{Controls}

None of the staining patterns described above were observed after incubation with DARPP-32 antibodies preabsorbed with purified DARPP-32 (Figs. $15 B$ and $16 F$ ) or normal rabbit serrum as a control for TH antiserum.

\section{Discussion}

The ontogeny of DARPP-32-LI in the prenatal rat CNS was investigated. This study was intended to detect DARPP-32 at its earliest stages of expression, irrespective of its cellular concentration. Recent studies show that although DARPP-32 is expressed at low levels prenatally, its concentration in rodent brain reaches a peak 3 weeks postnatally (N. L. Rosen, I. Shalaby, T. Kurihara, M. E. Erlich, H. C. Hemmings, Jr., and P. Greengard, unpublished observations). In general, the regions containing the major concentrations of strongly immunoreactive DARPP-32-positive neurons in the adult were first found to be immunoreactive on days $14-15$ of gestation, and were nearly fully represented by the day of birth. The only exceptions were the nucleus accumbens, where DARPP-32-immunoreactive neurons were first visible on day 18 of gestation, and the amygdaloid complex, where they failed to make an appearance until the day of birth. In the case of the nucleus accumbens, this may be because its close morphological association with the primordial caudate nucleus precludes a delineation of its exact boundarics prior to that timc.

The other regions bearing DARPP-32-positive cells, such as the caudate-putamen itself, the olfactory tubercle, the parietal cortex, and the primary olfactory cortex, all displayed immunoreactive somata by days 14 or 15 of gestation. This was only about $1 \mathrm{~d}$ later than the first appearance in cell bodies of the mesencephalon and medulla oblongata of the rate-limiting catecholamine synthetic enzymes TH (Specht et al., 1981a) and phenylethanolamine $N$-methyl-transferase (PMNT) (Foster et al., 1985a), and catecholamine histofluorescence (Olson and Seiger, 1972). 5 -HT is also first observed on about day 13 of gestation (Olson and Seiger, 1972). Thus, with regard to appearance in cell bodies, the ontogeny of DARPP-32-LI is not dissimilar temporally to that of the classical monoamine transmitters in the prenatal rat CNS.

The development of DARPP-32-positive fiber networks may also be followed during ontogeny of the rat CNS. The most prominent processes extended either to the ventral pallidal area and globus pallidus, or along the internal capsule to the substantia nigra. The density of innervation of this last area by DARPP-32-containing nerve fibers was similar at the day of birth to that found in the adult (Ouimet et al., 1984). DARPP32-immunoreactive processes were also demonstrable in the frontal, primary olfactory, and parietal cortices, and in the anterior commissure, the corpus callosum, and the fasciculus retroflexus leading from the medial habenula. Interestingly, a dense distribution of DARPP-32-positive fibers was visible on the day of birth in the thalamus (Fig. 11C). Their origin is unclear, but 





they may belong to corticothalamic projections whereby DARPP32-positive fibers in the subcortical white matter could represent the axons of these projections. Their disposition was reminiscent of the neuropeptide Y-positive system, with cells in the cortex and processes in the ventrolateral thalamus that are transiently visible in the embryonic brain (Foster and Schultzberg, 1984), but not in the adult (Chronwall et al., 1985).

The developmental pattern of DARPP-32-LI was not restricted to a gradual increase in cell numbers until a plateau was attained at the adult level; in many areas, even during the prenatal period, it was possible to observe a peaking of cell density and a subsequent reduction. A similar risc and fall in cell density associated with other transmitter-related substances has been previously reported (Hara et al., 1982; Inagaki et al., 1982; Foster and Schultzberg, 1984). This decline of DARPP-32-LI was not due entirely to an expansion of the tissue dimensions. The frontoparietal and cingulate cortices, in particular, all appeared to contain many more DARPP-32-positive somata on days 15 and 16 of gestation than on the day of birth. In addition, the intensity of their immunofluorescence was simultaneously attenuated, although our results obtained using immunocytochemical methods are not quantitative and must await biochemical studies of the quantitative development of DARPP32. Concurrent with the development of decreased cortical DARPP-32-LI, the immunoreactive neurons asssumed positions deeper in the cortex as development of the more superficial layers progressed. The neurons produced radially oriented DARPP-32-immunoreactive fibers that extended between layers I and VI, as seen in frontal sections. This arrangement was seen principally in the dorsolateral cortex.

In the adult, most DARPP-32-immunoreactive neurons are thought to receive some form of dopaminergic innervation (Ouimet et al., 1984). Thus, the caudate, nucleus accumbens, and olfactory tubercle all receive extensive dopaminergic inputs from the substantia nigra, while the immunopositive tanycytes of the median eminence may also be accessible to the influence of the dopaminergic dendrites they ensheathe (Piotte et al., 1985; Everitt et al., 1986). Similarly, in the 21-d-old fetus, for example, it is possible to visualize a sparse network of TH-containing fibers terminating close to the ventral part of the Sylvian aqueduct, an area in which many of the ependymal cells are DARPP-32-immunoreactive. However, no such innervation was found on the day of birth in the middle part of the third ventricle, at a time when significant numbers of DARPP-32-positive cells were displayed in this region. Furthermore, no contacts were found between dopamine-containing neurons and the choroid plexus. One possible explanation is that the cerebrospinal fluid may contain significant amounts of DA or of other substances whose actions may be mediated by DARPP-32, thus providing an input for these apparently nondopaminoceptive cells. That classical transmitters may circulate in the cercbrospinal fluid, possibly exerting neuronotrophic actions, has been repeatedly hypothesized in the past (for a review, see Lauder, 1983), and this may indeed be related to the function of the DARPP-32positive cells located in or near the cerebral ventricles. In this context, it is interesting that dopaminergic mechanisms may be involved in the control of choroid plexus blood flow (Townsend et al., 1984). In the arcuate region, no apparent contacts between DA neurons and DARPP-32-positive tanycytes were seen at birth, but distinct TH-positive processes can be seen in the adult rat between DARPP-32-positive ependymal cell bodies (Everitt et al., 1986).

The development of TH has also been analyzed immunocytochemically, in an effort to determine its temporal relationship with the ontogeny of DARPP-32-LI. TH-positive cell bodies are visible in the 13-d-old rat embryo, in the substantia nigra, and in the A1 and A2 regions of the medulla oblongata. This age is $1 \mathrm{~d}$ younger than when the first DARPP-32-immunoreactive neurons were seen. Therefore, it is unlikely that the transmitter phenotype of the dopaminergic neurons is governed by the presence of DARPP-32 in their future target areas. Similarly, it is unlikely that the occurrence of $\mathrm{TH}$ in cell bodies induces, per se, DARPP-32-containing cells in their respective terminal fields. In all the regions of the CNS that contain DARPP32-immunoreactive somata, such as the caudatoputamen, olfactory tubercle, primary olfactory cortex, and frontal cortex, the DARPP-32-LI is visible before the TH fibers have arrived. Although the amygdaloid complex does not represent a major DARPP-32-containing area prior to birth, DARPP-32-positive cells were also found there earlier than TH-containing afferents.

It might be suggested that the development of the dopaminergic terminal structures precedes the appearance of TH-LI within them, and that it is some other substance, perhaps on their surface, that is responsible for the induction of DARPP32 in the target neurons. However, the presence of TH-LI in the distal portions of neuronal processes even after blockade of axonal transport (Everitt et al., 1984), and our previous findings of a simultaneous morphological and immunocytochemical appearance of neurons of the embryonic medulla oblongata containing TH-LI (Foster et al., 1985a) would tend to militate against this idea. Further evidence against the hypothesis that the arrival of dopaminergic innervation might induce the production of DARPP-32-LI within target neurons is that many DARPP-32positive cells in the rat CNS receive no known DA-containing afferents. One example of such a region is the cerebellum, where DARPP-32-LI is present in the adult (Ouimet et al., 1984). The development of DARPP-32-LI appears, then, to be independent of a suitable dopaminergic input. Conversely, though, it is possible that the presence of DARPP-32-LI in a presumptive dopaminoceptive cell may be related to the attraction and/or stabilization of the incoming dopaminergic afferents. Evidence compatible with this comes from data showing a 1 to $2 \mathrm{~d}$ delay between the appearance of DARPP-32-LI in cells of the caudate nucleus and the olfactory tubercle and the subsequent arrival of the TH-containing nerve terminals. In no region of the rat CNS did the appearance of TH afferents occur before that of

Figure 19. Immunofluorescence photomicrographs of TH-LI $(A)$ and DARPP-32-LI $(B)$ in adjacent sections of the caudate nucleus $(C P u)$ of the newborn rat brain. Numerous DARPP-32-positive cell clusters can be seen within the caudate nucleus, as well as a band of densely packed fluorescent cell bodies along the dorsolateral border (curved arrows) towards the forceps minor of the corpus callosum (fmi). DARPP-32-positive cell bodies and fibers are also seen in the olfactory tubercle $(T u)$, as well as in the medial forebrain bundle area $(m f b)$ and fundus striati $(F s t r i)$. Note fluorescent cell bodies in the primary olfactory cortex (arrows in $B$ ). $A c b$, accumbens nucleus; aca, anterior part of the anterior commissure $A$, Part of section adjacent to $B$. Note islands of densely packed $\mathrm{TH}$-immunoreactive fibers both in the $C P u$ and along its dorsolateral border (curved arrows). Small arrowhead in upper corner of $B$ points dorsally, big arrowhead medially. Bar, $50 \mu \mathrm{m}$. Both micrographs have the same magnification. 
the DARPP-32-positive somata (Specht et al., 1981; Berger and Verney, 1984). Furthermore, the reorganization of the DARPP32-positive cells in the caudate nucleus into several discrete clusters also preceded by 1 to $2 \mathrm{~d}$ a similar rearrangement of the already dense TH-immunoreactive terminal networks. Therefore, the appearance of DARPP-32 does not seem to be dependent on the presence of a dopaminergic innervation.

\section{References}

Berger, B., and C. Verney (1984) Development of the catecholamine innervation in rat neocortex: Morphological features. In Monoamine Innervation of Cerebral Cortex, L. Descarries, T. R. Reader, and H. J. Jasper, eds., pp. 95-121, Alan R. Liss, New York.

Chronwall, B. M., D. A. DiMaggio, V. J. Massari, V. M. Pickel, D. A. Ruggiero, and T. L. O'Donohue (1985) The anatomy of neuropeptide-Y containing neurons in rat brain. Neuroscience 15: 1159-1181.

Coons, A. H. (1958) Fluorescent antibody methods. In General $\mathrm{Cy}$ tochemical Methods, J. F. Danielli, ed., pp. 399-425, Academic, New York.

Everitt, B. J., T. Hökfelt, L. Terenius, K. Tatemoto, V. Mutt, and M. Goldstein (1984) Differential co-existence of neuropeptide Y (NPY)like immunoreactivity with catecholamines in the central nervous system of the rat. Neuroscience 11: 443-462.

Everitt, B. J., B. Meister, T. Hökfelt, T. Melander, L. Terenius, А̊. Rökaeus, E. Theodorsson-Norheim, G. Dockray, J. Edwardson, C. Cuello, R. Elde, M. Goldstein, H. Hemmings, C. Ouimet, I. Walaas, P. Greengard, W. Vale, E. Weber, J.-Y. Wu, and K. J. Chang (1986) The hypothalamic arcuate nucleus-median eminence complex: Immunohistochemistry of transmitters, peptides and DARPP-32 with special reference to coexistence in dopamine neurons. Brain Res. Rev. 11: $97-155$.

Foster, G. A., and M. Schultzberg (1984) Immunohistochemical analysis of the ontogeny of neuropeptide $\mathrm{Y}$ immunoreactive neurons in foetal rat brain. Int. J. Dev. Neurosci. 2: 387-407.

Foster, G. A., M. Schultzberg, M. Goldstein, and T. Hökfelt (1985a) Ontogeny of phenylethanolamine $N$-methyltransferase- and tyrosine hydroxylase-like immunoreactivity in presumptive adrenaline neurons of the fetal rat central nervous system. J. Comp. Neurol. 236: 348-381.

Foster, G. A., M. Schultzberg, D. Dahl, M. Goldstein, and A. A. J. Verhofstad (1985b) Ephemeral existence of a single catecholamine synthetic enzyme in the olfactory placode and spinal cord of the embryonic rat. Int. J. Dev. Neurosci. 3: 597-608.

Hara, Y., S. Shiosaka, E. Senba, M. Sakanaka, S. Inagaki, H. Takagi, Y. Kawai, K. Takatsuki, T. Matzuzaki, and M. Tohyama (1982) Ontogeny of the neurotensin-containing neuron system of the rat: Immunohistochemical analysis. I. Forebrain and diencephalon. J. Comp. Neurol. 208: 177-195.

Hemmings, H. C., Jr., and P. Greengard (1986) DARPP-32, a dopamine and adenosine $3^{\prime}: 5^{\prime}$-monophosphate-regulated phosphoprotein: Regional, tissue and phylogenetic distribution. J. Neurosci. 6: 1469-1481.

Hemmings, H. C., Jr., P. Greengard, H. Y. L. Tung, and P. Cohen (1984a) DARPP-32, a dopamine-regulated neuronal phosphoprotein, is a potent inhibitor of protein phosphatase-1. Nature 310:502505.

Hemmings, H. C., Jr., A. C. Nairn, D. W. Aswad, and P. Greengard (1984b) DARPP-32, a dopamine and adenosine $3^{\prime}, 5^{\prime}$-monophosphate-regulated phosphoprotein enriched in dopamine-innervated brain regions. II. Purification and characterization of the phosphoprotein from bovine caudate nucleus. J. Neurosci. 4: 99-110.

Inagaki, S., M. Sakanaka, S. Shiosaka, E. Senba, K. Takatsuki, H. Takagi, Y. Kawai, H. Minagawa, and M. Tohyama (1982) Ontogeny of substance P-containing neuron system of the rat: Immunohistochemical analysis. I. Forebrain and upper brain stem. Neuroscience 7:251277.

Johnson, D. G., and G. M. De C Nogueira Araujo (1981) A simple method of reducing the fading of immunofluorescence during microscopy. J. Immunol. Methods 43: 349.

Köhler, G., and C. Milstein (1975) Continuous cultures of fused cells secreting antibody of predefined specificity. Nature 256: 495-497.

Lauder, J. M. (1983) Hormonal and humoral influences on brain development. Psychoneuroendocrinology 8: 121-155.

Markey, K. A., S. Kondo, I. Shenkman, and M. Goldstein (1980) Purification and characterization of tyrosine hydroxylase from a clonal phaeochromocytoma cell line. Mol. Pharmacol. 17: 79-85.

Nauta, W. J. H., and V. B. Domesick (1979) The anatomy of the extrapyramidal system. In Dopaminergic Ergot Derivatives and Motor Function, K. Fuxe and D. B. Calne, eds., pp. 3-22, Pergamon, Elmsford, New York.

Olson, L., and A. Seiger (1972) Early pre-natal ontogeny of central monoamine neurons in the rat: Fluorescence histochemical observations. Z. Anat. Entwickl. Geschrift. 137: 301-316.

Ouimet, C. C., P. E. Miller, H. C. Hemmings, Jr., S. I. Walaas, and P. Greengard (1984) DARPP-32, a dopamine and adenosine $3^{\prime}: 5^{\prime}$ monophosphate-regulated phosphoprotein enriched in dopamine-innervated brain regions. III. Immunocytochemical localization. J. Neurosci. 4: 111-124.

Paxinos, G., and C. Watson (1982) The Rat Brain in Stereotaxic Coordinates, Academic, New York.

Pease, P. F. (1962) Buffered formaldehyde as a killing agent and primary fixative for electron microscopy. Anat. Rec. 142: 342 .

Piotte, M., A. Beaudet, T. Joh, J. R. Brawer (1985) The fine structural organization of tyrosine hydroxylase immunoreactive neurons in rat arcuate nucleus. J. Comp. Neurol. 239: 44-53.

Specht, L. A., V. M. Pickel, T. H. Joh, and D. J. Reis (1981a) Lightmicroscopic immunocytochemical localization of tyrosine hydroxylase in prenatal rat brain. I. Early ontogeny. J. Comp. Neurol. 199: 233-253.

Specht, L. A., V. M. Pickel, T. H. Joh, and D. J. Reis (1981b) Light microscopic immunocytochemical localization of tyrosine hydroxylase in prenatal rat brain. II. Late ontogeny. J. Comp. Neurol. 199: $255-276$.

Townsend, J. B., D. M. Ziedonis, R. M. Bryan, R. W. Brennan, and R. B. Page (1984) Choroid plexus blood flow: Evidence for dopaminergic influence. Brain Res. 290: 165-169.

Walaas, S. I., and P. Greengard (1984) DARPP-32, a dopamine- and adenosine $3^{\prime}: 5^{\prime}$-monophosphate-regulated phosphoprotein enriched in dopamine-innervated brain regions. J. Neurosci. 4: 84-98.

Walaas, S. I., A. C. Nairn, and P. Greengard (1983) Regional distribution of calcium- and adenosine $3^{\prime}: 5^{\prime}$-monophosphate-regulated protein phosphorylating systems in mammalian brain. II. Soluble systems. J. Neurosci. 3: 302-311.

Zamboni, L., and C. de Martino (1967) Buffered picric-acid formaldehyde: A new rapid fixative for electron-microscopy. J. Cell Biol. 35: $148 \mathrm{~A}$. 